\title{
CRÓNICA DE JURISPRUDENCIA DEL TRIBUNAL EUROPEO DE DERECHOS HUMANOS, AÑO 2015
}

\author{
MARTA CABRERA MARTÍN ${ }^{1}$
}

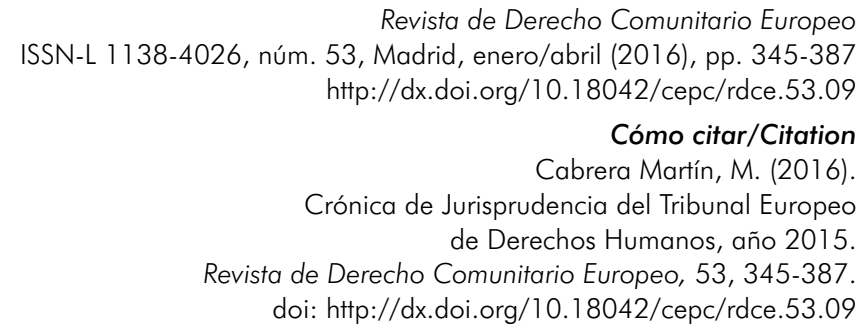

I. INTRODUCCIÓN. II. PRINCIPALES SENTENCIAS Y DECISIONES DEL TEDH PRONUNCIADAS EN EL AÑO 2015: 1. Derecho a la vida (art. 2 del CEDH); 2. Derecho a no ser sometido a tortura ni a penas o tratos inhumanos o degradantes (art. 3 del CEDH); 3. Derecho a la libertad y a la seguridad (art. 5 del CEDH); 4 . Derecho a un proceso equitativo (art. 6 del CEDH); 5 . Irretroactividad de la ley penal (art. 7 del CEDH); 6. Derecho al respeto a la vida privada y familiar (art. 8 del CEDH): A. Derecho a la vida privada; B. Derecho a la vida familiar; 7. Libertad de expresión (art. 10 del $\mathrm{CEDH}$ ); 8. Libertad de expresión y libertad de reunión y asociación (arts. 10 y 11 del CEDH); 9. Derecho a contraer matrimonio (art. 12 del CEDH); 10. Protección de la propiedad (art. 1 del Protocolo 1 al CEDH). III. REFERENCIAS AL DERECHO DE LA UE EN LA JURISPRUDENCIA DEL TEDH. IV. ESPAÑA Y EL TRIBUNAL EUROPEO DE DERECHOS HUMANOS: 1. Sentencias; 2. Decisiones de inadmisibilidad.

1 Letrada de apoyo del Tribunal Europeo de Derechos Humanos. 


\section{INTRODUCCIÓN}

La presente crónica tiene como objeto servir de referencia sobre la prolífica actividad jurisprudencial del Tribunal Europeo de Derechos Humanos (en adelante, «TEDH»o «el Tribunal») a lo largo del pasado año 2015.

En primer lugar, se realizará un análisis de las sentencias y decisiones más relevantes por su impacto en el desarrollo del contenido, naturaleza y ámbito de aplicación de los derechos contenidos en el Convenio Europeo de Derechos Humanos (en adelante, «CEDH» o «el Convenio»). Dicha jurisprudencia ha sido sistematizada siguiendo como patrón inicial el orden de los artículos plasmados en el Convenio.

El siguiente apartado está destinado a comentar aquellos pronunciamientos en los que el Tribunal ha analizado instrumentos legales y jurisprudencia de la Unión Europea como etapa previa para fundamentar algunos de sus fallos, lo que sin duda demuestra la creciente convergencia en el ámbito de los Derechos Humanos entre ambas jurisdicciones.

Finalmente, también se ha considerado relevante realizar un somero resumen de las sentencias y decisiones más relevantes del Tribunal recaídas en el año 2015 en asuntos contra España.

\section{PRINCIPALES SENTENCIAS Y DECISIONES DEL TEDH PRONUNCIADAS EN EL AÑO 2015}

\section{DERECHO A LA VIDA (ART. 2 DEL CEDH)}

Uno de los asuntos que mayor repercusión ha generado a lo largo de este año ha sido el caso Lambert y otros c. Francia ${ }^{2}$. La demanda ante el Tribunal fue presentada a mediados de 2014 por los padres de Vincent Lambert, quien en el año 2008 sufrió un accidente de tráfico en el que quedó tetrapléjico, en un estado vegetativo crónico y de "completa dependencia»"

En septiembre de 2013, el médico responsable del señor Lambert inició un procedimiento de consulta sobre los derechos del paciente y las cuestiones relativas a la terminación voluntaria de la vida. Tras varias reuniones con la familia y un equipo de seis médicos, la esposa del señor Lambert y sus hermanos mostraron su conformidad con la retirada de la alimentación artificial. Los demandantes en el presente caso se opusieron. La presente controversia fue tramitada

2 Lambert and Others $v$. France [GC], núm. 46043/14.

3 Ibid., párr. 11. 
y analizada por el Consejo de Estado francés (Conseil d'État) a nivel interno, el cual respaldó el 24 de junio de 2014, tras la obtención de nuevos informes médicos, la decisión de retirar la alimentación artificial del señor Lambert.

Ante tal situación, los demandantes optaron por acudir al TEDH e interpusieron primeramente una solicitud de medidas cautelares de conformidad con el art. 39 del Reglamento del Tribunal, la cual fue estimada el 24 de junio de 2014. El Tribunal ordenó la suspensión de la ejecución de la sentencia dictada por el Consejo de Estado durante todo el periodo en el cual el caso estuviera siendo tramitado ante el Tribunal. En relación con el fondo de la demanda presentada ante el Tribunal, los demandantes alegaron que la retirada de la alimentación artificial contravendría el art. 2 del Convenio (derecho a la vida). En concreto, los demandantes centraron parte de esta argumentación en señalar las deficiencias de la legislación francesa y del procedimiento seguido para la toma de la decisión relativa a la retirada de la alimentación artificial.

El presente caso presenta varios aspectos interesantes, siendo uno de ellos la cuestión de la legitimación activa de los demandantes. Por primera vez, el Tribunal aceptó la legitimación activa de unos demandantes que actuaban en nombre de otro, el cual no había fallecido y del que no constaba voluntad expresa de presentar un asunto ante el Tribunal ${ }^{4}$. Asimismo, el Tribunal consideró que el presente caso no versaba sobre las obligaciones negativas del Estado francés al amparo del citado art. 2, sino sobre las obligaciones positivas de éste ${ }^{5}$.

Adicionalmente, el Tribunal observó que actualmente no existía un consenso entre los países miembros del Consejo de Europa a favor o en contra de la suspensión de tratamientos que alarguen la vida de manera artificial. Por tanto, según el Tribunal, los Estados gozaban de un amplio «margen de apreciación» a la hora no solo de autorizar o proscribir esta práctica, sino también en relación con los medios utilizados para realizar el juicio de ponderación entre la protección del derecho a la vida y la protección del derecho a la vida privada y autonomía personal ${ }^{6}$. El TEDH señaló que el procedimiento seguido para la toma de la decisión de la retirada de la alimentación artificial había sido realizado de conformidad con la legalidad vigente, que dicho marco legal era claro y preciso y que la decisión estaba detalladamente fundamentada ${ }^{7}$. Finalmente, en una decisión adoptada por 12 votos a favor y 5 en contra, la

\footnotetext{
Ibid., párr. 112.

Ibid., párr. 124.

Ibid., párrs. 148 y 168.

Ibid., párrs. 160, y 166 a 168, entre otros.
} 
Gran Sala del Tribunal declaró, entre otras, que el Estado no había violado el art. 2 del Convenio.

\section{DERECHO A NO SER SOMETIDO A TORTURA NI A PENAS O TRATOS INHUMANOS O DEGRADANTES (ART. 3 DEL CEDH)}

El 28 de septiembre de 2015 la Gran Sala del Tribunal emitió su sentencia en el caso Bouyid c. Bélgica ${ }^{8}$, la cual fue adoptada por 14 votos a favor y 3 en contra, y en la que el Tribunal determinó que la bofetada infligida por un miembro de la policía a los demandantes cuando se encontraban bajo el control de aquéllos había socavado su dignidad y constituyó trato degradante. Cabe señalar que en el presente caso la Gran Sala revocó la sentencia inicial de la Sala ${ }^{9}$, que previamente había declarado que no se había producido una violación del art. 3 del Convenio por cuanto el acto lesivo no había alcanzado el nivel mínimo de severidad necesario ${ }^{10}$.

Los demandantes eran dos hermanos (uno de ellos menor de edad en el momento de los hechos) que en dos ocasiones diferentes (uno el 8 de diciembre de 2003 y otro el 23 de febrero de 2004) fueron abofeteados por dos policías una vez trasladados a la estación de la policía local.

En particular, el Tribunal señaló que una bofetada infligida por un miembro de las fuerzas de seguridad del Estado a una persona sujeta al control de aquél constituía un serio ataque a la dignidad individual de la persona ${ }^{11}$. Asimismo, cabe señalar que ambos demandantes denunciaron los hechos y aportaron un certificado médico que constataba la presencia de moretones. No obstante, ambos oficiales fueron finalmente absueltos. Es por ello que el Tribunal también señaló que las autoridades nacionales no realizaron una investigación efectiva y a tiempo de lo sucedido, en contravención con el art. 3 en el ámbito procesal ${ }^{12}$ (procedural limb).

\section{DERECHO A LA LIBERTAD Y A LA SEGURIDAD (ART. 5 DEL CEDH)}

Durante 2015 el Tribunal también tuvo la oportunidad de continuar desarrollando su jurisprudencia en torno a los límites de la privación de libertad en el caso de una persona considerada «enajenada» (unsound mind) en

\footnotetext{
8 Bouyid v. Belgium [GC], núm. 23380/09.

9 Bouyid v. Belgium, núm. 23380/09.

10 Ibid., párrs. 47 a 49.

11 Bouyid v. Belgium [GS], supra, párrs. 101 a 103.

12 Ibid., párrs. 127 a 134.
} 
los términos del Convenio ${ }^{13}$. El caso M.S. c. Croacia (Núm. 2) ${ }^{14}$ versa sobre el confinamiento involuntario de una persona en un hospital psiquiátrico, en presunta violación del citado apartado e) del art. 5.1 del Convenio ${ }^{15}$. En el marco del procedimiento judicial relativo a la prolongación del confinamiento de la demandante, los tribunales nacionales habían designado a un abogado de oficio que representara los intereses de ésta. No obstante, dicho abogado no cumplió de manera diligente con las obligaciones inherentes a su oficio, ya que jamás visitó a la demandante y ésta no pudo poner de manifiesto los argumentos a su favor. Asimismo, la demandante no fue informada en ningún momento de cuál era la vía legal más apropiada para defender sus legítimos intereses. El abogado tampoco realizó ningún tipo de alegato a favor de ésta a lo largo del procedimiento. No obstante lo anterior, el juzgado ordenó finalmente la continuación del confinamiento.

Con respecto a la posible violación del art. 5.1.e), el Tribunal señaló que la mera designación de un abogado de oficio, el cual de facto no proveyó a la demandante con la asistencia jurídica necesaria, no cumplía con los requisitos necesarios de la «asistencia legal» de la que debía haber disfrutado ${ }^{16}$. Según el Tribunal, la representación legal efectiva de personas con discapacidad requiere una obligación reforzada de supervisión por parte de los tribunales nacionales de estos representantes legales ${ }^{17}$. Cabe añadir que la demandante también había manifestado haber sido objeto de malos tratos (en particular, una retención efectuada por los trabajadores del hospital por duración de más de quince horas, y la deliberada falta de atención médica ante las quejas por los dolores que sufría en espalda y estómago) y que los tribunales nacionales no habían iniciado una investigación efectiva de sus quejas.

El Tribunal determinó, por tanto, que el Estado croata había violado el art. 3 del Convenio en su aspecto sustantivo y procesal, calificando el trato sufrido por la demandante como inhumano y degradante ${ }^{18}$, así como el art. 5.1.e) del Convenio.

Otro asunto que merece ser destacado es el caso Constancia c. Países Ba$j o s^{19}$, en el cual el Tribunal declaró inadmisible una demanda que versaba sobre la detención de una persona calificada como "persona enajenada» en ausencia

13 En concreto, en relación con el apartado «e» del art. 5.1 del Convenio.

14 M.S. v. Croatia (núm. 2), núm. 75450/12.

15 «[...] Nadie puede ser privado de su libertad, salvo en los casos siguientes [...]: e) Si se trata de la privación de libertad, conforme a derecho, [...] de un enajenado [...].»

16 M.S. v. Croatia (núm. 2), supra, párr. 154.

17 Idem.

18 Ibid., párrs. 85, 102 y 112.

19 Constancia v. The Netherlands (dec.), núm. 73560/12. 
de un diagnóstico preciso del estado mental del demandante. En el año 2006, el demandante fue procesado por la muerte de un alumno de primaria. En el marco del procedimiento penal, el demandante se negó a cooperar con las autoridades para determinar su estado mental, por lo que no se pudo obtener un diagnóstico del mismo. No obstante, los tribunales nacionales determinaron que el demandante sí padecía un trastorno mental y fue condenado a 12 años de prisión seguido de su confinamiento en una clínica como "persona enajenada». El demandante adujo que la detención en calidad de "persona enajenada» había contravenido el apartado e) del art. 5.1 del Convenio por cuanto no había sido diagnosticado como una persona con una incapacidad mental (mentally unfit).

Para fundamentar dicha decisión, los tribunales acudieron a numerosos informes ya existentes de psiquiatras y psicólogos, así como a la reproducción de las grabaciones audiovisuales de los interrogatorios ${ }^{20}$. Todo lo anterior permitió al Tribunal fundamentar su decisión de internamiento del demandante, lo cual fue conforme al citado apartado e) del art. 5.1 del Convenio. La relevancia del presente caso radica en que es el primero en el que el Tribunal ha admitido como alternativa al examen médico del estado mental de la persona, la información ya existente con respecto a esta.

\section{DERECHO A UN PROCESO EQUITATIVO (ART. 6 DEL CEDH)}

El Tribunal tuvo oportunidad en 2015 de pronunciarse sobre la interpretación realizada por los tribunales internos de una sentencia dictada por el TEDH y su conformidad con el art. 6 del Convenio en el caso Bochan $c$. Ucrania (núm. 2) ${ }^{21}$.

Cabe señalar primeramente que con fecha 3 de mayo de 2007 el Tribunal dictó una sentencia que afectaba a las mismas partes ${ }^{22}$, en virtud de la cual el Tribunal declaró que el Estado ucraniano había violado el art. 6.1 del Convenio debido a que las decisiones adoptadas en el marco del procedimiento interno se habían realizado sin las garantías de independencia e imparcialidad, legalidad y debida motivación, propias de las garantías de todo juicio justo. A la luz de dicha sentencia, el demandante interpuso a nivel interno un «recurso a la vista de las circunstancias excepcionales» («appeal in the light of exceptional circumstances»), solicitando al Tribunal Supremo ucraniano la revocación de las decisiones nacionales adoptadas en su caso y la admisión de todas sus quejas. En marzo de 2008

\footnotetext{
20 Ibíd., párr. 30.

21 Bochan v. Ukraine (núm. 2) [GC], núm. 22251/08.

22 Bochan v. Ukraine, núm. 7577/02.
} 
el Tribunal Supremo desestimó el recurso planteado tras determinar que las decisiones nacionales habían sido correctas y estaban debidamente razonadas. A la vista de lo anterior, la demandante acudió nuevamente ante el TEDH, alegando violación del art. 6.1 del Convenio y del art. 1 del Protocolo 1 (protección de la propiedad), argumentando que el Tribunal Supremo no había tenido en cuenta el fallo del TEDH.

A este respecto, la Gran Sala del Tribunal sostuvo, en primer lugar, que correspondía al Comité de Ministros supervisar la ejecución de las sentencias dictadas por el Tribunal y que, por tanto, excedía de la competencia del Tribunal analizar el eventual incumplimiento por parte de un Estado de las sentencias dictadas por el Tribunal ${ }^{23}$. Por tanto, esta parte de la demanda se declaró inamisible ratione materiae ${ }^{24}$. No obstante $-\mathrm{y}$ he aquí lo relevante-, el demandante además había esgrimido que se había producido una nueva violación del derecho a un juicio justo (art. 6.1 del Convenio) en la tramitación del recurso excepcional, arguyendo que la argumentación empleada por el Tribunal Supremo contradecía la jurisprudencia del TEDH. Esta parte de la demanda sí fue declarada admisible y el Tribunal consideró que dicho procedimiento estaba sometido a las garantías que dimanan del art. 6 del Convenio, toda vez que, a la luz de la legislación ucraniana y la naturaleza y alcance del procedimiento extraordinario de revisión, el procedimiento se consideraba como «decisivo para la determinación de los derechos y obligaciones civiles del demandante» ${ }^{25}$.

Sentado lo anterior, el Tribunal observó que, efectivamente, el Tribunal Supremo había interpretado erróneamente el fallo del TEDH de 3 de mayo de 2007, por cuanto señalaba que el TEDH había declarado que las decisiones nacionales habían sido conforme a derecho y estaban debidamente razonadas y que se había otorgado la debida compensación a la demandante por la violación de la garantía de que la causa fuera escuchada en un «tiempo razonable» (cuando lo cierto es que esa parte de la demanda había sido inadmitida en la sentencia). Estas afirmaciones, por tanto, demostraron ser visiblemente incorrectas y, según el Tribunal, extremadamente arbitrarias ("grossly arbitrary»), lo cual implicaba una «denegación de justicia»" ${ }^{26}$ El Tribunal, por tanto, concluyó de manera unánime que dicho procedimiento excepcional no satisfizo las garantías de un proceso equitativo contenidas en el art. 6.1 del Convenio.

\footnotetext{
23 Bochan v. Ukraine (núm. 2) [GC], supra, párrs. 54 y 55.

24 Ibid., párr. 35.

25 Ibid., párr. 56.

26 Ibid., párr. 64.
} 


\section{IRRETROACTIVIDAD DE LA LEY PENAL (ART. 7 DEL CEDH)}

En el caso Roblena c. República Checa $^{27}$ la Gran Sala del TEDH tuvo la oportunidad de pronunciarse sobre la compatibilidad de la aplicación de una reforma del código penal a hechos realizados con anterioridad y posterioridad a la entrada en vigor de dicha modificación, siempre y cuando fueran parte de un delito continuado. En el presente caso, el demandante alegaba que había sido condenado en virtud de lo preceptuado en el art. 215a del Código Penal, según su formulación de 1 de junio de 2004, por un delito continuado de «maltrato a una persona que vive bajo el mismo techo». En concreto, el demandante fue imputado por el referido delito de maltrato por hechos cometidos entre el año 2000 y el 8 de febrero de 2006.

El demandante acudió ante el TEDH invocando el art. 7 del Convenio y sosteniendo que los tribunales nacionales habían violado dicho artículo al aplicar el nuevo precepto del Código Penal a hechos ocurridos no solo con posterioridad a la reforma del mentado artículo sino también a hechos ocurridos con anterioridad.

Para analizar la presente cuestión, el Tribunal primeramente determinó que existía un consenso actual entre los Estados miembros del Consejo de Europa en cuanto al concepto de «delito continuado» y su forma de enjuiciamiento $^{28}$. Sentado lo anterior, la Gran Sala del Tribunal examinó si el delito estaba definido con suficiente previsibilidad. Para ello, el Tribunal destacó que el demandante había sido condenado por el delito por el que efectivamente fue imputado. El Tribunal observó que el Tribunal Supremo nacional había confirmado dicha condena al estimar que, al ser un delito continuado, el hecho en virtud del cual se procedía a la clasificación legal del delito era el último hecho punible que formara parte de dicho delito continuado, el cual en este caso se cometió una vez ya había entrado en vigor la reforma del Código Penal checo $^{29}$. Comoquiera que en el presente caso la conducta del demandante era ya punible bajo otros artículos (arts. 197a o 222.1 del Código Penal) y comprendía los elementos del tipo del enmendado art. 215a, el Tribunal aceptó que el hecho de condenar al demandante por hechos cometidos antes de la fecha de entrada en vigor de la reforma del código penal no constituyó una aplicación retroactiva de una ley penal desfavorable $e^{30}$. A este respecto, el Tribunal concluyó que el delito por el que había sido condenado el demandante

27 Rohlena v. the Czech Republic [GC], núm. 59552/08.

28 Ibid., párr. 33.

29 Ibid., párr. 59.

30 Ibid., párr. 62. 
tenía una base en el derecho nacional cuando fue cometido y que la ley estaba redactada de una manera lo suficientemente clara como para satisfacer el requisito de la previsibilidad contenido en el significado autónomo de la palabra «ley» plasmada en el art. 7 del Convenio ${ }^{31}$.

Por otro lado, el Tribunal también analizó si la condena impuesta al amparo del art. 215a era más severa que la que hubiera obtenido al aplicar a los hechos cometidos con anterioridad a junio de 2004 el Código Penal antiguo. Sobre la base de lo ya dictaminado por los tribunales nacionales (y, en concreto, por el Tribunal Supremo checo en su sentencia de 21 de febrero de 2008), el Tribunal concluyó que todos los elementos constitutivos del delito recogido en los párrafos 1 y 2 del art. 215a también estaban tipificados en el anterior Código Penal. Por ello, la Gran Sala del Tribunal declaró que el hecho de que los actos cometidos con anterioridad a la entrada en vigor de la nueva reforma fueran analizados al amparo de la nueva reforma no había causado una desventaja al demandante en lo que respecta a la condena ${ }^{32}$. Todo lo anterior permitió a la Gran Sala confirmar la sentencia dictada por la Sala de la Sección Quinta el 18 de abril de $2013^{33}$ y declarar que el Estado checo no violó el art. 7 del Convenio.

\section{DERECHO AL RESPETO A LA VIDA PRIVADA Y FAMILIAR (ART. 8 DEL CEDH)}

\section{A. Derecho a la vida privada}

Con respecto al derecho a la vida privada y familiar consagrado en el art. 8 del Convenio cabe mencionar en primer lugar el caso Y.Y. c. Turquía ${ }^{34}$, en el cual el Tribunal analizó la compatibilidad del derecho a la vida privada con el requisito de que el demandante acreditara que ya no podía procrear para así poder obtener una autorización para someterse a una operación de cambio de sexo. Este requisito derivaba de lo estipulado en el art. 40 del Código Civil turco. Si bien finalmente la demandante obtuvo la autorización para dicha operación, esta no se obtuvo hasta varios años después de arduo litigio ante los tribunales nacionales.

Con base en numerosos tratados internacionales, jurisprudencia del Tribunal e instrumentos de soft law europeos e internacionales, así como tras la realización de un estudio de derecho comparado sobre la legislación actual en

\footnotetext{
Ibid., párr. 64.

Ibid., párr. 69.

33 Rohlena v. the Czech Republic, núm. 59552/08.

34 Y.Y. v. Turkey, núm. 14793/08.
} 
treinta y dos Estados miembros del Consejo de Europa con respecto al acceso de las personas transexuales a una operación de cambio de sexo, el Tribunal concluyó que el rechazo inicial por parte de las autoridades turcas tuvo repercusiones sobre el derecho a la identidad sexual y el desarrollo de la persona, aspectos que, según el Tribunal, son fundamentales en el derecho al respeto a la vida privada. Asimismo, el Tribunal recordó la jurisprudencia recaída en el caso Christine Goodwin c. Reino Unido, en el cual el Tribunal ya había considerado que la transexualidad posee un amplio reconocimiento internacional como condición médica que justifica un tratamiento destinado a ayudar a las personas concernidas ${ }^{35}$.

A continuación, el Tribunal señaló que dicho rechazo había constituido una injerencia en el sentido del art. 8.1 del $\mathrm{CEDH}^{36}$, y que la misma tenía una base legal ${ }^{37}$. No obstante lo anterior, en relación a si dicho rechazo era «necesario en una sociedad democrática», el Tribunal consideró que el rechazo por parte de las autoridades turcas de no permitir el acceso al cambio de sexo durante tantos años no estuvo justificado suficientemente («à supposer même que le rejet de la demande initiale du requérant tendant à accéder à la chirurgie de changement de sexe reposait sur un motif pertinent, la Cour estime qu'il ne saurait être considéré comme fondé sur un motif suffisant $»^{38}$ ) y violó el art. 8 del Convenio ${ }^{39}$ en relación con su derecho a la propia identidad sexual y el libre desarrollo de la persona.

Lo interesante del presente caso radica en que es la primera vez que el Tribunal ha tenido la oportunidad de analizar la compatibilidad del art. 8 del Convenio con las condiciones impuestas a aquellas personas que deseen un cambio de sexo, ya que en anteriores supuestos el Tribunal solo había analizado las justificaciones esgrimidas en torno a las restricciones impuestas a las personas transexuales una vez realizada la operación de cambio de sexo ${ }^{40}$.

Por último, debemos hacer referencia al caso Szafranski c. Polonia ${ }^{41}$, relativo a la insuficiente distancia de separación de unas instalaciones sanitarias, y en el que el Tribunal desestimó la alegada violación del art. 3 (prohibición de tratos inhumanos o degradantes) pero estimó la violación del art. 8 (derecho

\footnotetext{
35 Christine Goodwin v. the United Kingdom [GC], núm. 28957/95, párr. 81.

36 Y.Y. c. Turquí, supra, párr. 66.

37 Ibid., párr. 71.

38 Ibid., párr. 121.

39 Ibid., párr. 122.

40 Véase, por ejemplo, Christine Goodwin v. the United Kingdom [GC], supra, párr. 90; Van Kück v. Germany, núm. 35968/97, párr. 69, ECHR 2003-VII, y Hämäläinen v. Finland [GC], núm. 37359/09, párr. 67.

41 Szafranski v. Poland, núm. 17249/12.
} 
al respeto a la vida privada) desde la óptica de las obligaciones positivas de los Estados.

El demandante se quejaba bajo los arts. 3 y 8 del Convenio de que sus condiciones de detención eran inadecuadas, toda vez que en 7 de las 10 celdas donde permaneció detenido las instalaciones sanitarias estaban separadas del resto de la celda por una división de fibra de un metro y veinte centímetros de alto que carecía de puertas y que, además, estaban situadas en la entrada de la celda. Si bien el Tribunal determinó que no se había producido una violación del art. 3 del Convenio, el Tribunal, por primera vez, declaró que el Estado polaco había violado las obligaciones positivas derivadas del art. 8 del Convenio en tanto no había asegurado al demandante un mínimo de privacidad cuando estuvo detenido ${ }^{42}$. El Tribunal se basó, inter alia, en las recomendaciones del Comité Europeo para la Prevención de la Tortura y de las Penas o Tratos Inhumanos o Degradantes (en adelante, "CPT»), el cual ya ha declarado en numerosas ocasiones que no es aceptable que una celda ocupada por más de un detenido disponga de una instalaciones sanitarias separadas únicamente de manera parcial ${ }^{43}$.

\section{B. Derecho a la vida familiar}

Con respecto al derecho a la vida privada y familiar consagrado en el art. 8 del Convenio, cabe mencionar primeramente el caso Paradiso y Campanelly c. Italia ${ }^{44}$, el cual versa sobre la retirada de la guardia y custodia a los padres de un bebé nacido a través de una gestante subrogada (también llamada «madre de alquiler»).

Los demandantes eran un matrimonio italiano que, ante la imposibilidad de tener hijos de manera natural, viajaron a Rusia para contactar con una gestante subrogada que diera a luz a su hijo. En febrero de 2011 nació el bebé, fruto de una fecundación in vitro realizada con dos embriones que, en teoría, pertenecían a los demandantes. Tras el nacimiento del niño, la gestante subrogada dio su consentimiento escrito para que el niño fuera inscrito como hijo de ambos demandantes. En dicho certificado de nacimiento no se hizo mención alguna al hecho de que se había producido gracias a la gestación subrogada. Al llegar de vuelta a Italia, los demandantes solicitaron la correspondiente inscripción del certificado de nacimiento en el registro italianúm. Las autoridades italianas se percataron inmediatamente de que el certificado

42 Ibid., párrs. 39 y 40.

43 Véanse, entre otros, las recomendaciones CPT/Inf (2012) 13 y CPT/Inf (92) 3.

44 Paradiso and Campanelli v. Italy, núm. 25358/12. 
contenía información falsa sobre la verdadera filiación del niño y denegaron la inscripción del mismo. En mayo de 2011, a raíz de una solicitud por parte de las autoridades italianas de entregar el certificado de nacimiento, se inició a una investigación por «falsedad del estado civil» y violación de la legislación de adopción, por cuanto, según las autoridades italianas, el bebé había sido introducido en el país en contravención de la ley y la autorización que habían obtenido para adoptar, la cual no contemplaba la adopción de un menor de tan corta edad.

Asimismo, tras la realización de las correspondientes pruebas de $\mathrm{ADN}$, se determinó que no existía ningún tipo de vínculo biológico entre el señor Campanelli (quien de buena fe creía que su esperma había sido utilizado para la fertilización in vitro) y el niño. Finalmente, en octubre de 2011 el Tribunal de Menores, sobre la base de lo alegado por las partes y las pruebas genéticas, decidió retirar la guardia y custodia a los demandantes, entregarlo a los servicios sociales italianos y les prohibió todo tipo de contacto ${ }^{45}$. En abril del año 2013 los tribunales nacionales declararon legítimo el haber rechazado la solicitud de inscripción registral del certificado de nacimiento ruso y ordenó la expedición de un nuevo certificado de nacimiento, el cual indicaba expresamente que el bebé no tenía ningún progenitor reconocido. Asimismo, se le otorgó un nuevo nombre. Los tribunales nacionales consideraron que los demandantes habían tratado de introducir un bebé en el país en violación de los estándares internacionales sobre adopción y en violación de la legislación italiana. En el momento de presentación de la demanda ante el Tribunal existía un nuevo procedimiento de adopción, del cual los demandantes no pudieron formar parte.

En primer lugar, cabe señalar que el Tribunal declaró que los demandantes no tenían legitimación para interponer la demanda en nombre del niño, toda vez que había quedado demostrado que los demandantes no tenían ningún vínculo biológico con este y que además les habían retirado la guardia y custodia desde el 20 de octubre del año $2011^{46}$. El Tribunal, por tanto, analizó únicamente la eventual violación del art. 8 del Convenio en nombre de los propios demandantes.

A este respecto, el Tribunal consideró que: i) haber rechazado el reconocimiento de las relaciones paterno-filiales generadas en el extranjero, ii) la retirada de la guardia y custodia y iii) la puesta a disposición del bebé a cargo de la Administración, había constituido una injerencia en el derecho de los demandantes a la vida privada, indicando, asimismo, que dicho concepto

45 Ibid., párrs. 22 y 23.

46 Ibid., párrs. 45 a 50. 
incluía el «derecho a establecer relaciones con otros» ${ }^{47}$. Esta injerencia había sido realizada de conformidad con la ley (y ello con base en la legislación que emana del derecho internacional privado y la adopción internacional) y perseguía un fin legítimo, ya que fue realizada como medida de «defensa del orden» (prevention of disorder), pues los demandantes habían realizado una práctica que en ese momento era ilegal en Italia ${ }^{48}$.

No obstante lo anterior, el Tribunal tuvo que determinar a continuación si las medidas adoptadas con respecto al bebé (en particular, la retirada de la guardia y custodia, asumida por la Administración) podían considerarse como proporcionadas (esto es, «necesarias en una sociedad democrática»), teniendo en cuenta si se había priorizado ante todo el interés superior del niño ${ }^{49}$.

Si bien el Tribunal entendió que las medidas adoptadas por los tribunales nacionales tenían como objetivo dar fin a una situación ilegal, las medidas en sí no habían resultado justificadas. Así, el Tribunal consideró que no era suficiente con que los demandantes hubieran sido imputados por la comisión de un delito y que no era comprensible que el niño no hubiese tenido una "existencia oficial» durante más de dos años. El Estado italiano tenía la obligación de asegurar que el bebé no se encontrara en una situación de desventaja por el hecho de haber nacido a través de una madre subrogada, sobre todo en relación con las cuestiones de identidad y ciudadanía ${ }^{50}$. En consecuencia, el Tribunal consideró que las justificaciones brindadas por las autoridades italianas para motivar la entrega del bebé a la Administración fueron insuficientes ${ }^{51}$.

No obstante lo anterior, a la vista de que el bebé ya había desarrollado lazos emocionales con su nueva familia adoptiva desde que fue entregado a esta a principios del año 2013, el Tribunal indicó expresamente que la declaración de violación del art. 8 no implicaba la obligación por parte del Estado de devolver al bebé a los demandantes ${ }^{52}$. Cabe señalar que esta decisión fue adoptada por una mayoría de cinco votos a favor y dos en contra y, además, ha sido remitida a la Gran Sala el 1 de junio de 2015.

\footnotetext{
47 «This includes, to a certain degree, the right to establish relationships with others» (ibíd., párr. 70).

8 Ibid., párrs. 72 y 72.

49 Ibid., párrs. 73 y 74.

50 Ibid., párr. 85.

51 Ibid., párr. 86

52 Ibid., párr. 88.
} 
Siguiendo en la línea de las relaciones paterno-filiales, también cabe destacar el caso Nazarenko c. Rusia ${ }^{53}$, en el cual el Tribunal tuvo la oportunidad de pronunciarse sobre el ámbito de aplicación del art. 8 del Convenio en las relaciones entre padre e hijo que carecen de un nexo biológico.

A lo largo de su matrimonio, el demandante había tenido junto con su mujer un bebé. La pareja se divorció y ambos acordaron la custodia compartida de la hija. Posteriormente, a raíz de un proceso de impugnación de paternidad, se determinó que el demandante no era el padre biológico de la niña. A pesar de que los tribunales nacionales reconocieron que el demandante había criado a la niña durante cinco años, acordaron privarle de la patria potestad e incluso le prohibieron mantener contacto con la niña.

El Tribunal nuevamente reiteró que el concepto de vida familiar (family life) no estaba limitado a las relaciones derivadas del matrimonio, toda vez que podía abarcar otro tipo de lazos "familiares» ${ }^{54}$. También hizo referencia a su jurisprudencia precedente en los casos Moretti y Benedetti c. Italia ${ }^{55}$ y Kopfy Liberda c. Austria ${ }^{56}$, en los que el Tribunal determinó que las relaciones entre una familia de adopción y el/la niño/a adoptad/o entraban dentro del ámbito de protección del concepto de vida familiar amparado por el art. 8.1 del Convenio.

En el presente caso, el Tribunal consideró que, efectivamente, la relación existente entre el demandante y la niña entraba dentro de este ámbito de protección ${ }^{57}$. Sentado lo anterior, el Tribunal pasó a analizar si el Estado había dado cumplimiento a sus obligaciones positivas y negativas. A este respecto, el Tribunal observó con preocupación la rigidez de la legislación del Estado ruso en cuanto al derecho a comunicarse (contact rights). Como resultado de ello, una persona como el demandante, que hubiera cuidado de un niño por un largo periodo de tiempo y que no tuviera un nexo biológico con el mismo no tendría derecho a ningún tipo de comunicación con este, independientemente de cuál fuera el interés superior del niño ${ }^{58}$. El Gobierno no dio razones de por qué esta medida tan restrictiva debía ser considerada como «necesaria en una sociedad democrática».

El Tribunal determinó que el Estado ruso no cumplió con las obligaciones derivadas del art. 8 del Convenio al no haber examinado la cuestión de si

\footnotetext{
53 Nazarenko v. Russia, núm. 39438/13.

54 Ibid., párr. 56.

55 Moretti and Benedetti v. Italy, núm. 16318/07.

56 Kopf and Liberda v. Austria, núm. 1598/06.

57 Ibid., párr. 58.

58 Ibid., párr. 65.
} 
el contacto entre el demandante y la niña podía servir al interés superior del niño ${ }^{59}$. Además, el Tribunal consideró que la persona que había criado a la niña como hija suya por un periodo largo de tiempo no podía ser completamente excluida de la vida de esta, salvo que hubiera razones de peso relacionadas con el interés superior del niño ${ }^{60}$. Muy al contrario, las autoridades de atención infantil, así como varios informes psicológicos, habían determinado que existía un nexo emocional muy fuerte entre el demandante y la niña y que el demandante había cuidado de ella diligentemente.

Por todo lo anterior, el Tribunal concluyó que el Estado ruso violó el art. 8 del Convenio al no permitir al demandante la posibilidad de mantener un nexo familiar con la niña ${ }^{61}$. El interés del presente caso radica en que el Tribunal analiza cuestiones novedosas en cuanto al ámbito de protección de las personas con lazos familiares que carecen de vínculos biológicos entre ellas. Asimismo, también confirma la apuesta del Tribunal por que las prohibiciones automáticas sobre cuestiones que afecten al derecho a la vida familiar sean sometidas a un riguroso escrutinio en los casos en los que esté en juego el interés superior del niño.

Por otro lado, en el caso Khoroshenko c. Rusia $a^{62}$, el Tribunal analizó la compatibilidad del derecho a la vida privada y familiar con la situación del demandante, un prisionero condenado a cadena perpetua sometido a un restrictivo régimen de comunicación con el exterior.

En 1995 el demandante fue sentenciado a pena de muerte por asesinato. Dicha condena fue sustituida por una pena de cadena perpetua y fue transferido a una prisión con un régimen especial: durante los primeros diez años, el demandante fue sometido a un "régimen estricto», en virtud del cual solo tenía derecho a dos visitas familiares anuales de cuatro horas con dos miembros de la familia como máximo. En dichos encuentros, el demandante y sus familiares estaban separados por un cristal y la visita era supervisada por un guardia de vigilancia penitenciaria. Asimismo, si bien el demandante podía mantener correspondencia con el mundo exterior, tenía prohIbído realizar cualquier tipo de llamada telefónica, salvo en caso de emergencia. Sobre la base del art. 8 del Convenio, el demandante alegó que el régimen estricto al que estuvo sometido era contrario a la protección que dicho precepto otorga al derecho a la vida privada y familiar.

59 Ibid., párr. 66.

60 Ibid., párr. 67.

61 Ibid., párr. 68.

62 Khoroshenko v. Russia [GC], núm. 41418/04. 
El Tribunal observó al respecto que, a nivel europeo, Rusia era el único país en el cual se concedía un régimen tan estricto y de tan poca frecuencia de visitas. En estos casos, los Estados gozan de un menor margen de apreciación a la hora de determinar los límites permisibles dentro de la esfera del derecho a la vida privada y familiar ${ }^{63}$.

En contraposición a lo que había declarado el Tribunal Constitucional ruso, el TEDH estimó que la combinación de restricciones impuestas al demandante había empeorado la situación de este en comparación con cualquier otro prisionero ruso medio. El Tribunal quedó impresionado (struck) ante la severidad y larga duración de las restricciones impuestas al demandante ${ }^{64}$. El Tribunal reiteró su jurisprudencia relativa a los derechos de los prisioneros al señalar que éstos deben poder disfrutar de todos sus derechos y libertades fundamentales garantizados en el Convenio, salvo, claro está, el derecho a la libertad ${ }^{65}$. El Tribunal tomó nota de la jurisprudencia del Tribunal con respecto al contenido del art. 8, así como de otros instrumentos internacionales y de la práctica de tribunales nacionales e internacionales, los cuales reconocían de manera inequívoca un estándar mínimo de lo que se considera un nivel de contacto con las familias «aceptable» $\mathrm{o}$ "razonablemente bueno», independientemente del tiempo de condena del prisionero ${ }^{66}$. Asimismo, el Tribunal observó que el presente régimen era contrario a las recomendaciones del CPT y a lo recogido en el art. 10.3 del Pacto Internacional de Derechos Civiles y Políticos, del cual Rusia era parte desde el año 1973, así como otros instrumentos internacionales ${ }^{67}$.

En cuanto a las alegaciones del Gobierno en las que se indicaba que dichas restricciones tenían como objetivo la "reforma del delincuente» ${ }^{68}$, el Tribunal observó que dicha injerencia en el derecho a la vida privada y familiar basada únicamente en la gravedad de su condena fue desproporcionada al

\footnotetext{
63 Ibid., párr. 136.

64 Ibid., párr. 140.

65 Ibid., párr. 116.

66 Ibid., párr. 143

67 A este respecto, cabe destacar que parte del interés del presente caso radica en el hecho de que la sentencia realiza un resumen interesante de la jurisprudencia del Tribunal en relación con las visitas en prisión, un análisis útil sobre los estándares establecidos por instituciones del Consejo de Europa (donde destacan las recomendaciones del $\mathrm{CPT}$ ), por organismos de la ONU así como por la Comisión Interamericana de Derechos Humanos, y contiene además un informe comparativo en 36 Estados sobre el contenido del derecho a las visitas en prisión en los casos de prisioneros condenados a cadena perpetua.

Ibid., párr. 99.
} 
pretendido fin legítimo invocado por el Gobierno ${ }^{69}$. En particular, el Tribunal indicó que el efecto de esta medida se había visto intensificado por la larga duración del periodo en el que fue aplicado, así como por las reglas específicas que regulaban las visitas, tales como la prohibición absoluta de contacto físico, la separación a través de una pared de cristal o barrotes de metal, la continua presencia de un guardia de vigilancia penitenciaria durante las visitas, así como el límite máximo de visitantes adultos ${ }^{70}$. Lo anterior había supuesto una gran dificultad para el demandante para mantener el contacto con su hijo y con sus padres durante un periodo donde era crucial para todas las partes mantenerlo ${ }^{71}$. A lo anterior se añadió el hecho de que otros parientes y miembros lejanos de la familia tenían simplemente prohibido visitarle durante todo este largo periodo.

A la vista de todo lo anterior, el TEDH consideró que la medida no había realizado un balance justo (struck a fair balance) entre, por un lado, el derecho del demandante a la protección de su vida privada y familiar y, por otro, el fin perseguido por el Gobierno ${ }^{72}$. En el presente caso, el Tribunal determinó claramente que los Estados tienen la obligación de ser "proactivos» en relación con el fin de reinserción que debe tener la prisión, lo que incluye la obligación de intentar "compensar los efectos desociabilizadores» propios de la prisión ${ }^{73}$.

En otro orden de cosas, también cabe destacar que en 2015 el Tribunal tuvo la oportunidad de pronunciarse sobre los derechos de las parejas homosexuales en el ámbito del art. 8 del Convenio, en relación con el derecho al reconocimiento legal de las uniones homosexuales. En el caso Oliari y otros $c$. Italia ${ }^{74}$, los demandantes, tres parejas homosexuales, acudieron al Tribunal alegando, con base en una violación de los arts. 8, 12 (derecho a contraer matrimonio) y 14 (prohibición de discriminación) que debido a la actual legislación italiana no disponían de la posibilidad de contraer matrimonio u otro tipo de unión civil. El Tribunal recordó la jurisprudencia establecida en cuanto a la protección que otorga el art. 8, en su acepción de vida privada y vida familiar, a las parejas homosexuales ${ }^{75}$. Asimismo, el TEDH observó que,

\footnotetext{
Ibid., párr. 146.

Idem.

Ibid., párr. 147.

Ibid., párr. 148.

Ibid., párr. 144.

Oliari and Others v. Italy, núms. 18766/11 y 36030/11.

75 Ibid., párr. 103: «It is undisputed that the relationship of a same-sex couple, such as those of the applicants, falls within the notion of 'private life' within the meaning of Article 8. Similarly, the Court has already held that the relationship of a cohabiting
} 
si bien desde diciembre de 2013 las parejas homosexuales tenían la posibilidad de suscribir un contrato de cohabitación (cohabitation agreement), este tenía un ámbito de derechos muy limitado (tales como los derechos hereditarios, obligaciones de manutención, etc. $)^{76}$.

Por otro lado, el Tribunal indicó que existía un conflicto entre la realidad social de los demandantes, que vivían de manera abierta su relación, y su imposibilidad para obtener un reconocimiento legal de dicha relación ${ }^{77}$. Asimismo, el Tribunal realizó un análisis comparado de la situación legal de las parejas homosexuales en los países miembros del Consejo de Europa, concluyendo que existía una tendencia hacia el reconocimiento legal de este tipo de relaciones ${ }^{78}$. El Tribunal también consideró relevante para su decisión el hecho de que, actualmente, una mayoría de la población italiana apoyaba el reconocimiento legal de las parejas homosexuales ${ }^{79}$. Por último, también cabe señalar la importancia otorgada por el Tribunal a los pronunciamientos realizados a nivel interno por parte del Tribunal Constitucional y de Casación italianos, quienes ya habían urgido al poder legislativo a fin de que adoptara las medidas legales oportunas para otorgar un reconocimiento legal a las parejas homosexuales.

A la vista de todo lo anterior, el Tribunal concluyó de manera unánime que el Estado italiano había excedido su margen de apreciación y que había incumplido su obligación positiva de garantizar que los demandantes dispusieran de un marco legal específico que reconociera y protegiera su vínculo sentimental ${ }^{80}$, y que, por tanto, se había producido una violación del art. 8 del Convenio.

\section{LIBERTAD DE EXPRESIÓN (ART. 10 DEL CEDH)}

El caso Haldimann y otros $c$. Suiza $a^{81}$ versa sobre la condena a cuatro periodistas por haber realizado un programa de investigación en el que, con ayuda de una cámara oculta, entrevistaron a un corredor de seguros como parte

same-sex couple living in a stable de facto partnership falls within the notion of 'family life' (see Schalk and Kopf, cited above, párr. 94). It follows that the facts of the present applications fall within the notion of "private life" as well as 'family life' within the meaning of Article 8».

76 Ibid., párr. 169.

77 Ibid., párr. 173.

78 Ibid., párr. 178.

79 Ibid., párr. 181.

80 Ibid., párr. 185.

81 Haldimann and Others v. Switzerland, núm. 21830/09. 
de un programa de televisión sobre las prácticas en el mundo de venta de seguros de vida. En concreto, los demandantes fueron condenados en el marco de un procedimiento penal por grabar conversaciones de terceras personas sin autorización a 12 días de multas de entre 80 euros y 290 euros, mientras que el cuarto demandante recibió una pena suspendida de cuatro días de multa de 30 euros más un período de dos años de libertad provisional.

En el presente caso, el Tribunal tuvo que analizar por primera vez el uso por parte de periodistas de cámaras ocultas que graban la conducta de individuos con motivos de interés público. Tras determinar que las condenas se habían realizado de conformidad con la legalidad vigente ${ }^{82}$ y que dichas medidas se habían adoptado persiguiendo un legítimo objetivo (esto es, la protección de la reputación del corredor de seguros ${ }^{83}$ ), el Tribunal pasó a analizar si esta injerencia había sido «necesaria en una sociedad democrática». Cabe resaltar que el Tribunal se basó, entre otros, en los criterios establecidos en el caso de Gran Sala Axel Springer c. Alemania ${ }^{84}$ a la hora de analizar si los tribunales nacionales habían encontrado un balance justo (struck a fair balance) entre la libertad de los medios de comunicación y el derecho a la vida privada.

A diferencia del caso Axel Springer $A G$, donde la parte afectada en su derecho a la vida privada era un personaje público, en el presente caso la persona afectada era un individuo particular. El Tribunal observó que el propósito del programa no era exponer hechos de la vida privada del corredor de seguros, sino la de criticar y llamar la atención sobre las prácticas carentes de toda ética de los agentes de seguro ${ }^{85}$. El Tribunal destacó que los periodistas habían actuado guiados por motivos de interés públicos (donde los Estados disponen de un margen muy limitado a la hora de restringir el derecho a la libertad de expresión de conformidad con lo preceptuado en el párrafo segundo del art. 10 del $\mathrm{CEDH}^{86}$ ), que el corredor de seguros no era el objetivo del programa, que además se habían adoptado medidas que impedían la identificación del agente de seguros (como el haber pixelado su cara y haber distorsionado su voz) y que el uso de cámara oculta no estaba totalmente prohibido en la legislación nacional. Asimismo, nunca fue disputado el hecho de que el programa en sí reflejaba la realidad de las prácticas realizadas por la industria del seguro.

\footnotetext{
82 Ibid., párrs. 36 a 38.

83 Ibid., párrs. 41 a 43.

84 Axel Springer AG v. Germany [GC], núm. 39954/08.

85 Haldimann and Others $v$. Switzerland, supra, párrs. 56 a 58.

86 Ibid., párr. 59.
} 
Adicionalmente, el Tribunal observó que, si bien las multas impuestas en el marco de un procedimiento penal no eran de una cuantía excesiva, las mismas eran capaces de tener un efecto disuasorio (chilling effect) sobre los profesionales de los medios de comunicación que pretenden llamar la atención sobre asuntos de interés público ${ }^{87}$. Es por ello que el Tribunal concluyó, en decisión adoptada por seis votos a favor y uno en contra, que el Estado suizo violó el derecho a la libertad de expresión de los demandantes.

Otro caso relevante que analiza el ámbito de libertad de expresión de los periodistas es el caso Pentikäinen c Finlandia ${ }^{88}$, el cual examinó la detención y condena de un periodista que desobedeció las órdenes de los policías en una manifestación que estaba siendo dispersada. En este caso, la Gran Sala del TEDH confirmó la sentencia del año 2014 de la Sala de la Sección Cuarta del Tribunal al indicar que el Estado finlandés no había violado el art. 10 del Convenio. El demandante en cuestión acudió a cubrir en calidad de periodista/fotógrafo una manifestación de gran repercusión mediática durante la Conferencia Asia-Europa ("ASEM», según sus siglas en inglés) que tuvo lugar en Helsinki el 9 de septiembre de 2006.

El demandante fue arrestado y detenido durante diecisiete horas y media para posteriormente ser condenado por haber desobedecido órdenes policiales. El caso es interesante en cuanto analiza el ámbito de protección y las obligaciones al amparo del art. 10 de los periodistas que cubren una manifestación callejera. Es importante destacar que en el presente caso la sanción no versaba en concreto sobre la actividad del demandante como periodista, sino sobre su incumplimiento de una orden «legal y razonable» (disturbios y seguridad pública). La Gran Sala, tras destacar el rol esencial de "guardián» (en inglés, watchdog) de los periodistas según el cual toda injerencia sobre un periodista que cubre una protesta pública debe estar sujeto al más estricto escrutinio ${ }^{89}$, analizó las obligaciones y responsabilidades de los periodistas y las consecuencias derivadas de un periodismo responsable, afirmando que los periodistas no podían, en principio, estar exentos de su obligación de obedecer la legislación penal sobre la base de que el art. 10 les otorgaba una "protección de hierro" ${ }^{90}$.

La Gran Sala analizó la necesidad y razonabilidad de la medida adoptada por parte de la policía de dispersar a los manifestantes, el alcance de hasta dónde había podido informar el demandante sobre el evento en cuestión (ha-

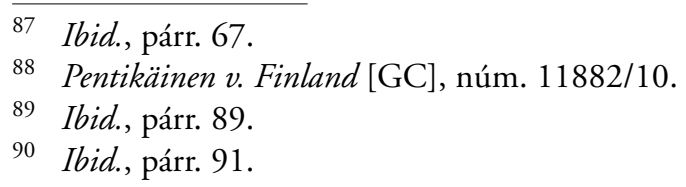


bía podido cubrir la mayor parte del evento) y la conducta del demandante. El Tribunal destacó que el demandante no portaba de manera visible su credencial de prensa al efecto de poder ser identificado claramente como periodista ${ }^{91}$. Asimismo, el Tribunal observó que el demandante era perfectamente consciente de que la policía había dado la orden de dispersar la manifestación y que él deliberadamente asumió el riesgo de no cumplir la orden, y ello a pesar de las numerosas advertencias realizadas por la policía ${ }^{92}$. En cuanto a la sanción impuesta, el Tribunal observó que, si bien la condena penal a un periodista constituía una injerencia grave, en el presente caso el demandante no había recibido ninguna sanción y que la condena tan siquiera formaría parte de sus antecedentes penales. En consecuencia, y en tanto la condena sólo implicó la declaración formal de que el demandante había cometido un delito, no se podía considerar que la misma hubiera tenido un efecto disuasorio (chilling effect) sobre las personas que participaban en la protesta o, en general, sobre el trabajo de los periodistas ${ }^{93}$.

También merece especial mención el caso Morice c. Francia ${ }^{94}$, en el cual el demandante, abogado, fue condenado a pagar una multa de 4.000 euros (más 7.500 euros a pagar a dos jueces entre él y otros dos acusados) por haber remitido al ministro de Justicia una carta en la que criticaban la conducta de dos jueces y dudaban de su imparcialidad y honestidad. El contenido de dicha carta fue publicado en el periódico Le Monde. Dichos jueces interpusieron una denuncia contra el editor jefe del periódico, el periodista que había redactado el artículo y el demandante por difamación pública de un funcionario.

Si bien en una sentencia de 11 de julio de 2013 la Sala de la Sección Quinta del TEDH había declarado que el Estado francés no había violado el art. 10 del $\mathrm{CEDH}^{95}$, la Gran Sala revocó dicho pronunciamiento con su sentencia de 2015, en la que sí declaró la violación del art. 10 del CEDH.

Tras determinar que la sanción impuesta al demandante estaba prevista en la ley y perseguía un fin legítimo, la Gran Sala determinó que, si bien las observaciones del demandante podían presentar una «naturaleza hostil», estas versaban sobre el funcionamiento de una investigación judicial, lo cual es un asunto de interés público que deja a los Estados poco margen para restrin-

\footnotetext{
Ibid., párr. 98.

Ibid., párr. 100.

Ibid., párr. 113.

Morice v. France [GC], núm. 29369/10.

Morice v. France, núm. 29369/10.
} 
gir el derecho a la libertad de expresión ${ }^{96}$. Asimismo, el Tribunal reafirmó la necesidad de que los abogados tuvieran la posibilidad de llamar la atención públicamente sobre las eventuales deficiencias del sistema judicial ${ }^{97}$. El Tribunal concluyó que las observaciones del demandante (consideradas como «juicios de valor» — value judgments - más que como afirmaciones sobre hechos — statement of facts - ${ }^{98}$ ) no habían constituido, además, ataques infundados sobre el comportamiento de varios miembros del poder judicial ${ }^{99}$. Adicionalmente, el Tribunal criticó la sanción impuesta al demandante, la cual tuvo como efecto determinante para ser más severa el hecho de que el demandante fuera abogado ${ }^{100}$. A la vista de todo lo anterior, el Tribunal consideró que la sentencia condenatoria por «complicidad en difamación» constituyó una injerencia desproporcionada en el derecho del demandante a la libertad de expresión y que, por tanto, no había sido «necesaria en una sociedad democrática» ${ }^{101}$.

Por el contrario, el TEDH consideró en el caso Delfi AS c. Estonia ${ }^{102}$ que la obligación por parte de una empresa de indemnizar a un tercero por los comentarios anónimos colgados en una página web de su propiedad no había constituido una violación del art. 10.1 del Convenio. Dicha sentencia viene a confirmar por parte de la Gran Sala lo ya declarado en este caso el 10 de octubre de 2013 por la Sala de la Sección Primera del Tribunal ${ }^{103}$.

El presente caso es relevante por cuanto ha sido la primera vez en la que el Tribunal ha tenido la oportunidad de analizar las quejas relativas a la responsabilidad por actividades realizadas por terceros en Internet.

En particular, la empresa demandante (uno de los mayores portales de noticias en Estonia) alegaba que su derecho a ofrecer información amparado por el art. 10.1 del Convenio se había visto infringido por cuando los tribunales nacionales le habían sancionado con una multa de 320 euros por comentarios anónimos publicados en su página web sobre una compañía de transporte marítimo. El portal de noticias procedió a eliminarlos tras recibir una denuncia de la víctima. Dichos comentarios fueron calificados por el Tribunal como discursos de incitación al odio (hate speech) y a la violencia ${ }^{104}$. El

\footnotetext{
96 Morice v. France [GC], supra, párr. 125.

Ibid.

98 Ibid., párr. 156.

99 Ibid., párr. 174

100 Ibid., párrs. 127 y 175.

101 Ibid., párr. 177.

102 Delf AS v. Estonia [GC], núm. 64569/09.

103 Delfi AS v. Estonia, núm. 64569/09.

104 Delfi AS v. Estonia [GC], supra, párr. 117.
} 
Tribunal también observó que los mismos se hicieron en una página web de amplia de difusión en el país ${ }^{105}$.

En otro orden de cosas, el Tribunal indicó además que en Estonia existía en esos momentos un marco legal previsible y que la demandante era por tanto consciente de que podía considerársele responsable por los comentarios que se colgaban en su portal ${ }^{106}$. Asimismo, el Tribunal observó que la demandante poseía el control para modificar e incluso borrar aquellos comentarios que considerara ofensivos, lo cual implicó que su participación en la publicación de dichos comentarios fue más allá de ser un simple actor pasivo. Tampoco se podía dejar de lado el hecho de que el demandante tenía obviamente un interés económico en la publicación de comentarios. La responsabilidad de la demandante fue entendida como una alternativa perfectamente posible ante un escenario en el cual los verdaderos autores de los mensajes permanecían en el anonimato. La empresa demandante tenía como obligación, por tanto, adoptar las medidas necesarias para limitar e incluso impedir la diseminación de discursos de odio o que inciten a la violencia ${ }^{107}$. Lo anterior no podía ser calificado como "censura privada» ${ }^{108}$.

Finalmente, en cuanto a la sanción de 320 euros impuesta a la demandante, el Tribunal concluyó que la misma en modo alguno podía ser calificada como desproporcionada ${ }^{109}$. A la vista de todo lo anterior, se puede concluir que el Tribunal admitió que un Estado puede requerir a un portal de noticias que monitorice los comentarios de los usuarios del mismo, de tal manera que los comentarios claramente ilícitos puedan ser eliminados inmediatamente, sin necesidad de que la víctima o un tercero tenga que notificárselo.

También se debe traer a colación el caso Perinçek c. Suiza ${ }^{110}$, en el cual la Gran Sala del TEDH tuvo la oportunidad de confirmar la sentencia recaída dos años antes y dictada por la Sala de la Segunda Sección sobre el derecho a la libertad de expresión en relación con las afirmaciones realizadas por un jurista de nacionalidad turca en torno a la masacre y deportación de los armenios por parte del Imperio otomano en 1915 y su condena penal. En concreto, el demandante defendió en varios eventos en Suiza, entre otros, que las alegaciones del llamado "genocidio turco» constituían una «mentira internacional», siendo condenado penalmente a pagar una multa, la cual podía ser sustituida por treinta días de prisión y una suma de dinero.

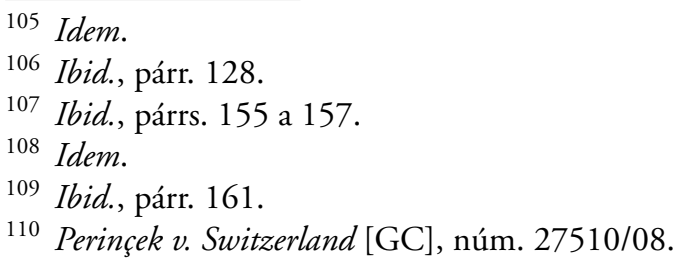


El presente caso es interesante en tanto que la Gran Sala señaló que lo esencial a la hora de analizar dicho caso no era determinar si la criminalización de la negación del genocidio armenio estaba per se justificada. Tampoco era rol de este Tribunal determinar si los eventos ocurridos en 1915 debían ser calificados como genocidio o si, por el contrario, las declaraciones del demandante constituían en sí una clara negación del genocidio armenio ${ }^{111}$. Muy al contrario, lo crucial en el presente caso, según el Tribunal, era determinar si las afirmaciones del demandante se podían considerar como incitadoras a la violencia, el odio o la intolerancia ${ }^{12}$.

El Tribunal, por tanto, a la vista de que las declaraciones efectuadas por el demandante no se realizaron en un contexto de alta tensión, que estas no podían considerarse como que afectaran a la dignidad de los miembros del pueblo armenio y que no había ninguna obligación internacional de criminalizar este tipo de declaraciones, concluyó que no era «necesario en una sociedad democrática» haber sancionado penalmente al demandante con el objeto de proteger los derechos de la comunidad armenia ${ }^{113}$. Según el Tribunal, los tribunales suizos censuraron una opinión del demandante que difería de la opinión establecida en Suiza ${ }^{114}$.

La singularidad del presente caso radica en la revisión que realiza el Tribunal en torno a aspectos particulares de su jurisprudencia relativa, entre otros, al art. 8 del Convenio en cuanto a la identidad de grupo y la reputación de los antepasados; al art. 10 del Convenio en relación con los discursos con incitación al odio y los debates históricos y a los arts. 10 y 17 del Convenio en lo referente a la denegación del Holocausto y otros crímenes cometidos por el régimen nazi.

\section{LIBERTAD DE EXPRESIÓN Y LIBERTAD DE REUNIÓN Y ASOCIACIÓN (ARTS. 10 Y 11 DEL CEDH)}

En este acápite resulta necesario hacer referencia al caso Petropavlovskis $v$. Latvia $^{115}$, en el cual el Tribunal tuvo la oportunidad de desarrollar su jurisprudencia relativa al ámbito de aplicación de los arts. 10 y 11 del Convenio. En el presente caso el demandante era un ciudadano no nacional con residencia permanente en Letonia. Este tipo de estatus se otorgaba a ciudadanos que

${ }^{111}$ Ibid., párr. 229.

112 Ibid., párr. 234.

113 Ibid., párr. 280.

${ }^{114}$ Idem.

115 Petropavlovskis v. Latvia, núm. 44230/06. 
pertenecían a la antigua Unión Soviética y que habían perdido su ciudadanía debido a la disolución de esta y no habían obtenido otra. El demandante era el líder de un movimiento de protesta en contra de las reformas educativas en Letonia en los años 2003 y 2004, defendiendo, entre otros, el derecho de las comunidades de habla rusa a recibir la educación en ruso y la preservación de los colegios públicos que disponían de la lengua rusa como la única lengua utilizada en la enseñanza. En el año 2004 el Comité de Ministros rechazó su solicitud para obtener la ciudadanía letona.

Tras ver rechazados todos los recursos, el demandante acudió ante el TEDH invocando los arts. 10 y 11 y alegando que el Estado letón había violado su derecho a la libertad de expresión y de reunión y asociación al negarle la obtención de la ciudadanía letona debido a su controvertida actividad política.

El Tribunal no obstante consideró que, de conformidad con la legislación internacional, las decisiones sobre naturalización de los ciudadanos eran cuestiones que pertenecían en principio a las jurisdicciones nacionales y que estas se basaban en criterios tales como el nexo entre el Estado y el solicitante ${ }^{116}$. Según el Tribunal, ni el CEDH ni ninguna otra norma de derecho internacional otorga de manera general el derecho a adquirir una nacionalidad específica, si bien un rechazo de la nacionalidad basado en una argumentación irracional podría ser, en determinadas circunstancias, contrario al art. 8 del Convenio ${ }^{117}$.

Asimismo, el Tribunal observó que el objetivo de la denegación por parte del Comité de Ministros de otorgar la nacionalidad al demandante no era la de castigarle, sino la de analizar la lealtad del demandante hacia el Estado y su Constitución ${ }^{118}$. El Tribunal finalmente concluyó que no existía motivo alguno para creer que al demandante se le impidió expresar libremente su desacuerdo con el Gobierno, así como pudo participar sin obstáculo alguno en las reuniones y manifestaciones al respecto ${ }^{119}$. A la vista de lo anterior, el Tribunal declaró que los arts. 10 y 11 no eran de aplicación al presente caso ${ }^{120}$.

\section{DERECHO A CONTRAER MATRIMONIO (ART. 12 DEL CEDH)}

En el caso Z.H. y R.H. c. Suiza ${ }^{121}$ el Tribunal analizó la compatibilidad de la decisión del Estado suizo de no reconocer el matrimonio religioso con-

116 Ibid., párr. 80

117 Ibid., entre otros, párrs. 73 y 83.

118 Ibid., párr. 85.

119 Ibid., párr. 86.

120 Idem.

121 Z.H. and R.H. v. Switzerland, núm. 60119/12. 
traído por los demandantes (un mayor de edad y una menor de 14 años) con el derecho a la vida familiar y el derecho a contraer matrimonio amparados en los arts. 8 y 12 del Convenio, respectivamente.

Los demandantes, de origen afgano, se habían casado en el año 2010 en Irán a través de un rito religioso, pero no disponían de ningún tipo de certificado. En el momento de contraer matrimonio la primera demandante tenía 14 años, mientras que el segundo demandante tenía 18 años. En el año 2011 solicitaron asilo en Suiza tras haberse registrado previamente como solicitantes de asilo en Italia. A lo largo del procedimiento de asilo, las autoridades suizas se percataron de que el matrimonio entre ambos demandantes no era compatible con las políticas públicas del país, por cuanto las relaciones sexuales con un menor de 16 años constituían un delito. Es por ello que los demandantes no podían invocar ningún derecho al amparo del art. 8 del Convenio.

Con respecto al citado art. 8 del Convenio, el Tribunal determinó que no existía ningún motivo para discrepar del planteamiento de los tribunales administrativos suizos en cuanto a la invalidez del matrimonio contraído por los demandantes ${ }^{122}$. Según el Tribunal, el art. 8 del Convenio no impone a los Estados la obligación de reconocer los matrimonios contraídos por menores de 14 años ${ }^{123}$. Dicha obligación tampoco se podía extraer del contenido del art. $12^{124}$. Por tanto, la decisión de las autoridades suizas de no reconocer el matrimonio fue justificada ${ }^{125}$.

El presente caso, si bien también realiza un análisis profundo sobre el derecho a la vida familiar en el ámbito del art. 8 del Convenio en relación con la expulsión del segundo demandante a Italia, es sobre todo interesante en relación con la respuesta dada a los demandantes en cuanto a su queja sobre la denegación de las autoridades suizas de reconocer su matrimonio por motivos de políticas públicas y, en particular, en cómo el Tribunal consideró que las autoridades suizas gozaban de una mejor posición para analizar las necesidades de la sociedad en un tema de tanta importancia como lo es la protección de la niñez y la necesidad de asegurar el entorno familiar ${ }^{126}$.

122 Ibid., párr. 44.

123 Idem.

124 Idem.

125 Idem, in fine.

${ }^{126}$ En particular, el Tribunal señaló lo siguiente (párr. 44): «Article 12 expressly provides for regulation of marriage by national law, and given the sensitive moral choices concerned and the importance to be attached to the protection of children and the fostering of secure family environments, this Court must not rush to substitute its own judgment in place of the authorities who are best placed to assess and respond to the needs of society (see B. and L. v. the United Kingdom, num. 36536/02, pár. 36, 13 September 2005)». 


\section{PROTECCIÓN DE LA PROPIEDAD (ART. 1 DEL PROTOCOLO 1 AL CEDH)}

En el caso Chiragov y otros c. Armenia ${ }^{127}$ el Tribunal, analizó, entre otros, las obligaciones positivas de los Estados en cuanto a la protección del derecho de todo ciudadano al disfrute pacífico (peaceful enjoyment) de sus bienes. Cabe señalar que la presente demanda recayó en un primer momento en la Sala de la Tercera Sección del Tribunal, la cual el 9 de marzo de 2010 se inhibió a favor de la Gran Sala.

Los demandantes son ciudadanos de Azerbaiyán de origen kurdo que vivían en el distrito de Lachin. En el año 1992 fueron víctimas de desplazamiento forzado como consecuencia del conflicto de Nagorno-Karabaj entre Armenia y Azerbaiyán. Los demandantes acudieron al Tribunal alegando, entre otros, que la posterior imposibilidad de volver a su casa atentó contra lo proveído en el art. 1 del protocolo 1 del Convenio.

Si bien el Tribunal consideró que el inicial desplazamiento forzado no entraba dentro de la jurisdicción temporal del Tribunal, sí podía examinar el posterior rechazo a acceder a su propiedad una vez el CEDH entró en vigor en Armenia (en 2002) y sí podía considerarse que se trataba de una violación continuada.

El Tribunal observó que los demandantes no habían tenido acceso a ningún tipo de remedio legal para obtener compensación por la pérdida de su propiedad o, en su caso, obtener un acceso a la propiedad que habían abandonado forzosamente tiempo atrás ${ }^{128}$. Es más, según el Tribunal, en la práctica no era realista pretender que personas azerbayainas volvieran a la región de Nagorno-Karabaj, toda vez que dicho territorio contaba con una presencia de tropas armenias, se produjeron varios incumplimientos del «alto al fuego» declarado y, en general, existía una relación hostil entre Armenia y Azerbaiyán en la que no se vislumbraba una solución política a corto plazo $^{129}$. En consecuencia, el Tribunal consideró que existía una continua injerencia en el derecho de los demandantes al disfrute pacífico de sus posesiones ${ }^{130}$.

Toda vez que el acceso a su propiedad no era posible, el Tribunal consideró que el Estado armenio tenía la obligación de adoptar medidas alternativas para asegurar los derechos de los demandantes. Según el Tribunal, el hecho de que existieran actualmente negociaciones de paz al amparo de la Organización para la Seguridad y la Cooperación en Europa (OSCE) no exoneraba al Estado armenio de su obligación de adoptar otras medidas, sobre todo si

127 Chiragov and Others v. Armenia [GC], núm. 13216/05.

128 Ibid., párr. 194.

129 Ibid., párr. 195

130 Ibid., párr. 196. 
se tenía en cuenta que dichas negociaciones se estaban llevando a cabo desde hacía más de veinte años ${ }^{131}$. Por todo lo anterior, el Tribunal consideró que era de suma importancia que los Estados introdujeran mecanismos accesibles que permitieran a los demandantes, y a otros en la misma situación que estos, la recuperación de sus derechos a la propiedad y a obtener una compensación por la pérdida sufrida en el disfrute de dichos bienes. Si bien el Tribunal reconoció que el Estado armenio había otorgado asistencia a cientos de miles de refugiados armenios y demás personas desplazadas, esto no eximía a dicho Gobierno de sus obligaciones para con los ciudadanos azerbaiyanos que habían tenido que huir como consecuencia del conflicto ${ }^{132}$, todo lo cual supuso una violación del art. 1 del protocolo 1 del Convenio ${ }^{133}$.

\section{REFERENCIAS AL DERECHO DE LA UE EN LA JURISPRUDENCIA DEL TEDH}

Tal y como veremos a continuación, el TEDH ha acudido en numerosas ocasiones a textos de la UE (derecho derivado, jurisprudencia, opiniones de grupos especializados, etc.) para analizar cuestiones de gran relevancia dentro del escenario europeo tan variable. Lo anterior sirve para ilustrar los innegables paralelismos existentes en la manera de interpretar los tratados de derechos humanos y observar cómo ambas jurisdicciones toman en consideración de manera creciente el enfoque de la otra en materia de protección de los derechos humanos.

Un primer ejemplo es el caso Parrillo c. Italia ${ }^{134}$, el cual fue tramitado ante la Gran Sala después de que el 28 de enero de 2014 la Sala de la Sección Segunda se inhibiera a favor de ésta, y que versa sobre la prohibición estatal de donar embriones para estudios científicos.

En este caso en particular, la demandante había recurrido a un tratamiento de fecundación in vitro en el año 2002. Su pareja falleció en 2003. Como quiera que ya no quería continuar con el procedimiento de fecundación, la demandante solicitó que le entregaran sus embriones para ella poder donarlos a un equipo de investigación científica. No obstante, con base en lo dispuesto en la Ley no 40 adoptada en el año 2004, la clínica se negó a entregárselos.

\footnotetext{
131 Ibid., párr. 198.

132 Ibid., párr. 200.

133 Cabe señalar que el fallo no fue unánime, sino que fue adoptado por una mayoría de 15 a 2.

134 Parrillo v. Italy [GC], núm. 46470/11.
} 
Con base en la protección otorgada por el art. 8 del Convenio y el art. 1 del protocolo número 1, la demandante acudió ante el TEDH para que este declarara la violación de dichos artículos. No obstante, el Tribunal, si bien consideró que el ámbito de aplicación del art. 8 sí cubría el derecho invocado por la demandante en el ámbito de respeto a la vida privada (siendo esta la primera vez que el Tribunal hacía un pronunciamiento a este respecto ${ }^{135}$ ), declaró que en este caso no se había producido una violación de dicho artículo, todo ello con base en el amplio margen de apreciación que gozaban los Estados para este tipo de casos en particular.

Antes de llegar a esta conclusión, el Tribunal realizó un estudio sobre el marco legal a este respecto en el ámbito de la Unión Europea. Así, en primer lugar hizo referencia a varias opiniones del Grupo Europeo de Ética de las Ciencias y de las Nuevas Tecnologías $\left(\mathrm{EGE}^{136}\right)$ de la Comisión Europea, así como al Reglamento (CE) na 1394/2007, de 13 de noviembre de 2007, sobre medicamentos de terapia avanzada y por el que se modifican la Directiva 2001/83/CE y el Reglamento (CE) no 726/2004, el cual en su apartado no 7 señalaba lo siguiente:

La reglamentación de los medicamentos de terapia avanzada a escala comunitaria no debe interferir con las decisiones de los Estados miembros para permitir o no el uso de cualquier tipo específico de células humanas (como las células madre embrionarias) o células animales. Tampoco debe afectar a la aplicación de la legislación nacional que prohíbe o restringe la venta, el suministro o el uso de medicamentos que consistan en dichas células, las contengan o deriven de ellas.

Asimismo, el Tribunal también hizo referencia a una sentencia de 18 de octubre de 2011 dictada por el Tribunal de Justicia de la Unión Europea ${ }^{137}$ (en adelante, «TJUE») que versaba sobre la interpretación de la Directiva 98/44/ EC del Parlamento Europeo y del Consejo de 6 de julio de 1998, relativa a la protección jurídica de las invenciones biotecnológicas. El Tribunal también analizó los principios éticos establecidos en la Decisión no 1982/2006/CE del Parlamento Europeo y del Consejo de 18 de diciembre de 2006, relativa al Séptimo Programa Marco de la Comunidad Europea para acciones de investigación, desarrollo tecnológico y demostración (2007 a 2013).

135 Véase, a contrario, Evans v. the United Kingdom [GC], núm. 6339/05, ECHR 2007-I, Costa and Pavan v. Italy, núm. 54270/10, y Knecht v. Romania, núm. 10048/10.

136 Por sus siglas en inglés, «European Group on Ethics and Science in New Technologies».

137 Sentencia Brüstle, C-34/10, EU:C:2011:669. 
En el caso Delf $A S c$. Estonia (ver resumen y análisis supra ${ }^{138}$ ) el Tribunal también acudió al contenido de varias Directivas ${ }^{139}$ así como a numerosa jurisprudencia del TJUE en relación con la responsabilidad de los dueños de los portales de Internet por el contenido que se publica en los mismos y, sobre todo, por los comentarios realizados por terceros. Con respecto a las Directivas, cabe señalar que la Gran Sala consideró que la demandante no podía ser calificada como un intermediario pasivo, sino más bien como una editorial, y ello sobre todo por el interés económico derivado de la publicación de comentarios. En consecuencia, el Tribunal consideró que el ámbito de aplicación de la Directiva sobre el comercio electrónico ${ }^{140}$, la cual eximía a los proveedores de servicios de internet de controlar los comentarios realizados por terceros, no cubría a la empresa demandante en particular ${ }^{141}$.

La Gran Sala del Tribunal también hizo un análisis de la jurisprudencia del TJUE en el caso Kudrevicius y otros c. Lituania ${ }^{142}$, el cual versa sobre el uso de vehículos para obstruir el tráfico en una manifestación. En el presente caso, el Tribunal declaró que los tribunales nacionales habían realizado un balance justo (struck a fair balance) entre, por un lado, el legítimo fin de «la defensa del orden" (prevention of disorder) y la "protección de los derechos y libertades de otros» $y$, por otro, los requisitos de la libertad de asociación, considerando además que las razones esgrimidas eran suficientes para justificar las medidas adoptadas.

Los demandantes eran unos agricultores que habían obtenido una autorización para realizar una protesta pública con el objeto de llamar la atención sobre la insuficiente respuesta dada por el Gobierno a los problemas acuciantes del sector agrario. Ante el estancamiento de las negociaciones con el Gobierno, los demandantes decidieron ir más allá de lo permitido por la autorización y bloquearon durante dos días tres autopistas principales. El bloqueo

138 Apdo. 7.

139 Directiva 2000/31/CE del Parlamento Europeo y del Consejo, de 8 de junio de 2000, relativa a determinados aspectos jurídicos de los servicios de la sociedad de la información, en particular el comercio electrónico en el mercado interior (Directiva sobre el comercio electrónico) (DO L 178, de 17 de julio de 2000, p. 1 ) y Directiva 98/34/ CE del Parlamento Europeo y del Consejo de 22 de junio de 1998 por la que se establece un procedimiento de información en materia de las normas y reglamentaciones técnicas, modificada por la Directiva 98/48/CE (DO L 204, de 21 de julio de 1998, p. 37).

140 Directiva 2000/31/CE del Parlamento Europeo y del Consejo, de 8 de junio de 2000, supra.

141 Ibid., párr. 198.

${ }^{142}$ Kudrevicius and Others v. Lithuania [GC], núm. 37553/05. 
fue levantado una vez el Gobierno accedió a sus demandas. Tras estos hechos, los demandantes fueron procesados y finalmente condenados a 60 días de cárcel, la cual fue suspendida, por haber cometido disturbios.

Los demandantes acudieron ante el Tribunal argumentando que la condena penal había violado su derecho a la libertad de expresión y su libertad de reunión y asociados, recogidos en los arts. 10 y 11 del Convenio, respectivamente. Con el objeto de sustentar su posición, los demandantes acudieron a diversos instrumentos emanados de instituciones de la Unión Europea. En particular, los demandantes señalaron que el bloqueo de carreteras era una cuestión aceptada en el seno de la Unión Europea como una forma válida de manifestación. Así, en primer lugar hicieron referencia al art. 2 del Reglamento (CE) no 2679/98 del Consejo, de 7 de diciembre de 1998, sobre el funcionamiento del mercado interior en relación con la libre circulación de mercancías entre los Estados miembros, el cual señala lo siguiente:

El presente Reglamento no debe interpretarse en el sentido de que afecta en modo alguno al ejercicio de los derechos fundamentales reconocidos en los Estados miembros, incluido el derecho o la libertad de huelga. Estos derechos podrán incluir asimismo el derecho o libertad de emprender otras acciones contempladas por los sistemas específicos de relaciones laborales en los Estados miembros.

Los demandantes también hicieron referencia a un informe de la Comisión Europea relativo a la aplicación de dicho Reglamento ${ }^{143}$, así como a la sentencia dictada en el caso Schmidberger ${ }^{144}$. El Tribunal analizó minuciosamente dicho caso ${ }^{145}$. El Tribunal señaló que no era necesario abordar los argumentos de las partes en cuanto a la determinación de si las medidas adoptadas por las autoridades podrían haber estado justificadas a la luz de la jurisprudencia del TJUE. El Tribunal precisó que el rol del TJUE era el de determinar si los Estados miembros de la Unión Europea cumplen con su obligación de asegurar la libre circulación de bienes, mientras que el rol del Tribunal en el presente caso era el de determinar si se había producido una violación de la libertad de reunión ${ }^{146}$.

143 Informe de 22 de marzo de 2001, COM (2001)160.

144 Sentencia Schmidberger (C-112/00, EU:C:2003:333).

145 Kudrevicius y Otros c. Lituania, supra, párrs. 73 a 76.

146 Ibid, párr. 184: "This conclusion dispenses the Court from addressing the arguments put forward by the parties in order to determine whether the measures adopted by the Lithuanian authorities could be justified in the light of the case-law of the ECJ (see paragraph 125 above for the applicants and paragraphs 134-135 above for the Government). In this connection, the Court confines itself to observing that the role 
El Tribunal también realizó un análisis de varias Resoluciones del Consejo de la Unión Europea y de jurisprudencia del TJUE en el caso Roman Zakharov c. Rusia ${ }^{147}$, en el cual el Tribunal declaró que el Estado ruso había violado el art. 8 del Convenio en relación con el marco legal que regulaba las medidas de vigilancia secreta de las comunicaciones, y, en concreto, las garantías necesarias que debían regir dichas medidas.

Para ello, el Tribunal analizó resoluciones del Consejo de la UE sobre la interceptación legal de las telecomunicaciones ${ }^{148}$ y sobre las necesidades operativas de las autoridades competentes sobre las redes y servicios públicos de telecomunicaciones ${ }^{149}$. Asimismo, el Tribunal realizó un análisis minucioso de la sentencia del TJUE recaída en el caso acumulado Digital Rights Ireland ${ }^{150}$, en virtud de la cual se declaró «inválida» la Directiva 2006/24 CE ${ }^{151}$ que establecía la obligación a los proveedores de servicios o redes públicos/as de comunicación de guardar todos los datos durante un periodo de seis meses a dos años con el objeto de que pudieran servir para perseguir delitos graves. En particular, el TJUE observó que, a pesar que la directiva no permitía la retención del contenido de las comunicaciones, sí que permitía el almacenamiento de los datos de tráfico y localización, lo cual revelaba datos de importancia sobre la vida privada de los ciudadanos. Por tanto, la obligación de retener dichos datos constituía por sí misma una injerencia en el derecho al respeto de la vida privada y familiar

of the ECJ was to establish whether the EU member States had complied with their obligation to ensure the free movement of goods, while the Court's task in the present case is to determine whether there has been an infringement of the applicants' right to freedom of assembly».

147 Roman Zakharov v. Russia [GC], núm. 47143/06.Roman Zakharov c. Rusia [GS], no 47143/06, 4 de diciembre de 2015.

148 Resolución del Consejo de 17 de enero de 1995 sobre la interceptación legal de las telecomunicaciones (96/C 329/01) (DO C 329, de 4 de noviembre de 1996, p. 1).

149 Resolución no 9194/01 del Consejo de 20 de junio de 2001 sobre las necesidades operativas de las autoridades competentes sobre las redes y servicios públicos de telecomunicaciones.

150 Sentencia Digital Rights Ireland ( C-293/12 y C-594/12, EU:C:2014:238).

151 Directiva 2006/24/CE del Parlamento Europeo y del Consejo de 15 de marzo de 2006 sobre la conservación de datos generados o tratados en relación con la prestación de servicios de comunicaciones electrónicas de acceso público o de redes públicas de comunicaciones y por la que se modifica la Directiva 2002/58/CE (DO L 105, de 13 de abril de 2006, p. 54). 
y a la protección de datos de carácter personal amparados por los arts. $7^{152}$ y $8^{153}$ de la Carta de los Derechos Fundamentales de la Unión Europea y el artículo. Si bien dicha directiva servía un propósito de interés general (esto eso, la lucha contra los crímenes graves y el terrorismo), la misma no cumplía con el requisito de proporcionalidad y, además, no disponía de suficientes garantías para asegurar la protección efectiva de los datos detenidos frente al acceso y uso ilegal y/o arbitrario de los mismos.

Por último, también cabe señalar la decisión de inadmisibilidad pronunciada en 2015 en el caso Laurus Invest Hungary KFT y Continental Holding Corporation c. Hungría ${ }^{154}$, en la cual los demandantes, 26 empresas con sede en Hungría y una con sede en Beverly Hills (Estados Unidos de América), invocaban la violación del art. 1 del Protocolo 1 del Convenio (derecho a la protección de la propiedad) y la violación de éste en conjunción con el art. 14 del Convenio (prohibición de discriminación), por cuanto en 2012 el parlamento húngaro había adoptado una ley que restringía las actividades de los salones recreativos. Varios demandantes habían demandado al Estado húngaro por las pérdidas derivadas de la aprobación e implementación de dicha ley, y ello con base en la legislación de la Unión Europea.

A lo largo del procedimiento judicial seguido ante los tribunales nacionales, el Tribunal Superior de Justicia de Budapest (Budapest High Court) presentó una cuestión prejudicial (preliminary ruling) ante el TJUE en relación con la compatibilidad de la nueva legislación y la manera en la que había sido implementada, con el derecho a la libre prestación de servicios protegido, entre otros, por el art. 56 del Tratado de Funcionamiento de la Unión Europea (en adelante, «TFUE»), el cual dispone lo siguiente:

En el marco de las disposiciones siguientes, quedarán prohibidas las restricciones a la libre prestación de servicios dentro de la Unión para los nacionales de los Estados miembros establecidos en un Estado miembro que no sea el del destinatario de la prestación.

El Parlamento Europeo y el Consejo, con arreglo al procedimiento legislativo ordinario, podrán extender el beneficio de las disposiciones del presente capítulo a los

152 «Toda persona tiene derecho a la libertad y a la seguridad».

153 «Toda persona tiene derecho al respeto de su vida privada y familiar, de su domicilio y de sus comunicaciones».

154 Laurus Invest Hungary KFT and Others v. Hungary (dec.), núms. 23265/13 and others. 
prestadores de servicios que sean nacionales de un tercer Estado y se hallen establecidos dentro de la Unión ${ }^{155}$.

En el referido caso ${ }^{156}$, el TJUE declaró, inter alia, que una eventual violación del citado art. 56 del TFUE daba derecho a compensación por el daño causado en aquellos casos en los que la violación se considerase «seria» y que hubiera un nexo directo entre la violación y el daño causado. El TJUE también determinó que una legislación nacional que restringiera el derecho amparado por el citado art. 56 también podía ser capaz de limitar el derecho de propiedad protegido por el art. 17 de la Carta de los Derechos Fundamentales de la Unión Europea ${ }^{157}$. En el momento de dictar sentencia el TEDH, el caso seguía siendo tramitado ante los tribunales nacionales.

El TEDH declaró que las demandas eran inadmisibles bien porque algunas de ellas habían sido presentadas de manera prematura, bien porque en otras no se habían agotado debidamente los recursos internos. El Tribunal estudió de manera minuciosa la sentencia dictada por el TJUE a este respecto y se centró en la manera en la que el TJUE había analizado la compatibilidad de las restricciones impuestas por la ley y las garantías protegidas por la Carta de los Derechos Fundamentales de la Unión Europea, así como en el razonamiento esgrimido en cuanto al derecho a compensación ${ }^{158}$. Asimismo, estudió la jurisprudencia de dicho tribunal en cuanto al carácter vinculante de las cuestiones prejudiciales ${ }^{159}$ observando, además, que dicha sentencia había otorgado cierta orientación a los tribunales húngaros en cuanto a los criterios que debían ser aplicados en el presente caso $^{160}$, una orientación la cual pre-

155 Ver también el art. 61 del TFUE, el cual señala que «[e]n tanto no se supriman las restricciones a la libre prestación de servicios, cada uno de los Estados miembros aplicará tales restricciones, sin distinción de nacionalidad o residencia, a todos los prestadores de servicios a que se refiere el párrafo primero del art. 56».

156 Sentencia Berlington Hungary y otros (C-98/14, EU:C:2015:386).

157 El citado artículo dispone lo siguiente: «1. Toda persona tiene derecho a disfrutar de la propiedad de sus bienes adquiridos legalmente, a usarlos, a disponer de ellos y a legarlos. Nadie puede ser privado de su propiedad más que por causa de utilidad pública, en los casos y condiciones previstos en la ley y a cambio, en un tiempo razonable, de una justa indemnización por su pérdida. El uso de los bienes podrá regularse por ley en la medida que resulte necesario para el interés general. 2. Se protege la propiedad intelectual».

158 Laurus Invest Hungary KFT y Continental Holding Corporation contra Hungria y otras 5 demandas, supra, párrs. 14 a 17.

159 Ibid., párrs. 27 y 37.

160 Ibid., párr. 39. 
sentaba cierta similitud con la posición de este Tribunal en cuanto al ámbito de protección del art. 1 del Protocolo $1^{161}$. Asimismo, destacó que el análisis realizado por el TJUE se basaba, al menos en parte, en la jurisprudencia del TEDH, lo que es fiel señal del creciente diálogo jurisprudencial entre ambos tribunales ${ }^{162}$.

El Tribunal declaró finalmente que pronunciarse sobre el asunto sin esperar a que lo hiciesen los tribunales húngaros con la orientación del TJUE supondría ignorar que su papel es subsidiario ${ }^{163}$.

\section{ESPAÑA Y EL TRIBUNAL EUROPEO DE DERECHOS HUMANOS}

En el año 2015, el Tribunal dictó con respecto a España 4 sentencias, 9 decisiones de inadmisibilidad y 4 decisiones de archivo. Asimismo, 22 casos fueron comunicados al Gobierno y 655 casos fueron declarados inadmisibles a través de la formación del Juez Único (Single Judge procedure). A continuación, realizaremos un somero repaso de aquellas sentencias y decisiones más relevantes.

\section{SENTENCIAS}

En este apartado es menester destacar primeramente la sentencia recaída en el caso Arribas Antón c. España ${ }^{164}$, en virtud de la cual el Tribunal tuvo la oportunidad de analizar la compatibilidad de un nuevo motivo de inadmisión del recurso de amparo ante el Tribunal Constitucional español con el derecho al acceso a los tribunales protegido por el art. 6.1 del Convenio. El demandante había denunciado, en particular, que su derecho al acceso a los tribunales se había visto vulnerado debido al nuevo motivo de inadmisibilidad introducido por la Ley Orgánica 6/2007, de 24 de mayo ${ }^{165}$, en virtud del cual se requería que el demandante de amparo justificase la «especial trascendencia constitucional» de su recurso. El demandante argumentó, inter alia, que la causa de inadmisión aducida era «excesivamente formalista».

161 Ibid., párr. 41.

162 Idem, in fine.

163 Ibid., párr. 42.

164 Arribas Antón v. Spain, núm. 16563/11.

165 Ley Orgánica 6/2007, de 24 de mayo, por la que se modifica la Ley Orgánica 2/1979, de 3 de octubre, del Tribunal Constitucional. 
El Tribunal, por su parte, tras analizar la interpretación jurisprudencial realizada por el propio Tribunal Constitucional al respecto, determinó que el fin pretendido por el cambio legislativo del año 2007 perseguía un fin legítimo $^{166}$. El Tribunal advirtió que las limitaciones impuestas a los recursos no debían restringir el acceso abierto al individuo hasta un punto tal que este derecho se vulnerase en su sustancia misma y que solo eran admisibles si perseguían un fin legítimo y si existía una relación razonable de proporcionalidad entre los medios empleados ${ }^{167}$. No obstante, también destacó lo siguiente:

[E]l TEDH recuerda que no le incumbe valorar la procedencia de las elecciones de política jurisprudencial operadas por las jurisdicciones internas, y que su papel se limita a comprobar la conformidad al Convenio de los efectos de dichas elecciones [...].

El TEDH recuerda al respecto que no puede ir contra el Convenio, el que una jurisdicción superior rechace un recurso limitándose a citar las disposiciones legales previstas en tal procedimiento, en tanto los problemas planteados por el recurso no revistan una trascendencia especial o si el recurso no tuviera suficientes visos de prosperar $[\ldots]$.

[E]l hecho de subordinar la admisibilidad de un recurso de amparo a la existencia de circunstancias objetivas y a su justificación por parte del recurrente, siendo éstos criterios previstos por la Ley e interpretados por la jurisprudencia constitucional - tales como la trascendencia de la causa para la interpretación, la aplicación o la eficacia general de la Constitución o para determinar el contenido y el alcance de los derechos (párrafo 29 anterior) — no es, como tal, desproporcionado o contrario al derecho de acceso al Tribunal Constitucional ${ }^{168}$.

A la vista de lo anterior, el Tribunal concluyó que el Estado español no vulneró el art. 6.1 del Convenio.

Por otro lado, el Tribunal también tuvo oportunidad de analizar en el caso Arratibel Garciandía c. España ${ }^{169}$ el cumplimiento de la obligación del Estado español de realizar una investigación efectiva de aquellos casos en los que un individuo afirmara de manera argumentada haber sido sometido a malos tratos contrarios al art. 3 del Convenio (prohibición de la tortura), de manos de la policía o de otros servicios equiparables del Estado. En el presente caso, el demandante fue detenido en su domicilio en la noche del 18 de enero de 2011 hacia las 3 de la mañana por agentes de la Guardia

166 Arribas Antón v. Spain, supra, párr. 49.

167 Ibid., párr. 41.

168 Ibid., párrs. 46 a 50.

169 Arratibel Garciandia v. Spain, núm. 58488/13. 
Civil, en el marco de una investigación judicial en torno a la presunta comisión de un delito de pertenencia a la organización EKIN, que formaba parte del grupo terrorista ETA. El demandante fue puesto en régimen de detención incomunicada cinco días, durante los cuales no pudo informar de dicha detención a ninguna persona de su elección, ni comunicarle el lugar de detención y no pudo ser asistido por ningún abogado elegido libremente, todo ello de conformidad con las normas aplicables a las detenciones en régimen de incomunicación.

Mientras estaba detenido, el demandante fue interrogado en varias ocasiones y afirmó haber sido objeto de amenazas, insultos y golpes ${ }^{170}$. El día 11 de marzo de 2011, el demandante presentó denuncia ante la jueza de guardia. El 27 de febrero de 2012 el Juzgado de Instrucción no 3 de Pamplona consideró, a la vista de los informes de los médicos forenses acerca del demandante y de la declaración de este último por videoconferencia, que no había indicios suficientes que demostraran que los malos tratos denunciados se hubieran infligido realmente, dictando por ello un auto de sobreseimiento.

El demandante acudió ante el TEDH alegando que el Estado español no había realizado una investigación efectiva respecto de su denuncia acerca de los presuntos malos tratos a los que habría sido sometido durante su detención, todo ello en contravención del art. 3 del Convenio.

A este respecto, el TEDH observó que los tribunales nacionales se limitaron a examinar los informes de los médicos forenses con respecto al demandante y la declaración de este último por videoconferencia, cuando este también había solicitado otros medios de prueba tales como: la copia de sus declaraciones ante la Guardia Civil y ante el juez central de Instrucción durante su detención en régimen de incomunicación, las eventuales grabaciones de las cámaras de seguridad de las dependencias en las que estuvo detenido, la identificación e interrogatorio de los agentes de la Guardia Civil implicados en la detención, la audiencia como testigos de los médicos forenses que le habían examinado y del abogado de oficio presente en sus declaraciones, así como ser sometido a examen físico y psicológico para sustanciar la existencia de eventuales lesiones o secuelas. Ninguna de estas pruebas fue practicada.

${ }^{170}$ En concreto, el demandante sostuvo que fue atado a una silla y sometido a episodios de asfixia con una bolsa de plástico que le cubría la cabeza, haber recibido golpes en los testículos y haber sido envuelto en una manta ajustada al cuerpo con cinta adhesiva y arrojado sobre un colchón (Ibid., párr. 9). 
A la vista de todo lo anterior, el TEDH consideró que «la investigación llevada a cabo en el presente caso no fue realizada con el suficiente detenimiento ni efectividad para que pudieran cumplir con los anteriormente citados requisitos exigidos por el art. 3 del Convenio» ${ }^{171}$, recalcando, además, que una investigación efectiva precisaba aún de mayor rigor si cabe en casos como el del demandante, el cual se encontraba en situación de incomunicación cuando tuvieron lugar presuntamente los malos tratos alegados $^{172}$. Asimismo, el Tribunal reiteró la importancia de «adoptar las medidas recomendadas por el CPT para mejorar la calidad del reconocimiento médico forense de las personas sometidas a detención en régimen de incomunicación» ${ }^{173}$

Por último, también se debe destacar el caso Blesa c. España ${ }^{174}$, el cual versa sobre la condena penal impuesta al demandante por falsificación de documentos y la alegada falta de imparcialidad de los magistrados encargados de enjuiciarle. En el año 2003, el demandante fue imputado por falsedad documental a raíz de una querella interpuesta en nombre de la Universidad de La Laguna, de la cual él era profesor en la facultad de Farmacia. En concreto, dicha institución le acusaba de haber falsificado su curriculum vitae para postular para un concurso público con el objetivo de adquirir una licencia farmacéutica. Si bien en febrero de 2004 el juez instructor decidió archivar provisionalmente la denuncia, dicha decisión fue revocada por la Audiencia Provincial de Santa Cruz de Tenerife, la cual remitió los autos para la celebración del juicio oral y nombró a los tres magistrados que formarían parte del mismo. Tras la celebración del juicio oral, la Audiencia Provincial declaró al señor Blesa culpable del delito imputado y le sentenció a tres años y seis meses de prisión, la inhabilitación especial para el ejercicio de cargo público durante el mismo periodo y una multa de 25 euros diarios durante ocho meses.

El señor Blesa recurrió dicha sentencia y alegó que el tribunal no había sido imparcial, toda vez que uno de los magistrados había formado parte del tribunal que conoció de la apelación adoptada por el acusado contra la suspensión de la instrucción de la causa penal. Además, el demandante también se quejó de que otro de los magistrados era profesor asociado empleado con funciones administrativas en la Universidad de La Laguna. El Tribunal Supremo desestimó el recurso aduciendo que, con respecto al primer magistrado, el demandante había tenido conocimiento de la composición del tribunal en

171 Ibid., párr. 39.

172 Idem.

173 Ibid., 40.

174 Blesa Rodríguez v. Spain, núm. 61131/12. 
junio de 2004 y que este podía haber recusado a dichos jueces con anterioridad. Con respecto al segundo magistrado, el Tribunal Supremo señaló que el demandante no había probado que dicho magistrado tenía interés alguno en el resultado del procedimiento. El Tribunal Constitucional desestimó el recurso de amparo sobre la base de que el demandante no había agotado debidamente los recursos internos.

Con respecto al primer magistrado, el TEDH declaró que el demandante, efectivamente, no agotó los recursos internos, por cuanto tanto el Tribunal Supremo como el Tribunal Constitucional desestimaron los respectivos recursos por no haber agotado las vías anteriores y no haber recusado a dicho juez en el momento que tuvo conocimiento de la composición del tribunal. Por tanto, de conformidad con los apartados 1 y 4 del art. 35 del Convenio, esta parte de la demanda fue declarada inadmisible ${ }^{175}$.

Con respecto al segundo magistrado, el TEDH sí consideró que el demandante había agotado debidamente los recursos internos y entró a analizar el fondo. El Tribunal observó que, efectivamente, dicho magistrado era profesor asociado de la universidad y que había realizado determinadas actividades administrativas por las cuales había recibido determinados pagos ${ }^{176}$. Sobre dicha base, el Tribunal consideró que dicho magistrado tenía una relación profesional remunerada con la universidad en el momento de enjuiciar al demandante. Es por ello que el Tribunal consideró que, si bien la conducta del magistrado superaba el test subjetivo de imparcialidad, lo cierto es que el mero hecho de haber tenido esa relación económica con el denunciante hacía que surgieran dudas en cuanto a la imparcialidad del mismo y, por tanto, no superaba el test objetivo ${ }^{177}$. El Tribunal concluyó que el Estado español violó el art. 6.1 del Convenio en relación con el derecho a ser juzgado por un tribunal imparcial.

\section{DECISIONES DE INADMISIBILIDAD}

Otro caso que merece ser destacado es el caso Soberanía de la Razón c. España ${ }^{178}$ en virtud del cual el Tribunal analizó los requisitos establecidos en el art. 169.3 de la Ley Electoral ${ }^{179}$ y el art. 5 de la instrucción de la Comisión

175 Ibid., párr. 28.

176 Ibid., párr. 44.

177 Ibid., párrs. 43 a 45.

178 Soberanía de la Razón v. Spain (dec.), núm. 30537/12.

179 Dicho artículo establece que los partidos políticos sin representación en el Congreso de los Diputados o en el Senado necesitarán la firma de al menos el $0,1 \%$ de los 
Electoral Central 7/2011 ${ }^{180}$ y su conformidad con el art. 3 del Protocolo 1 del Convenio. Los demandantes señalaban, en particular, que las limitaciones contenidas en dichos artículos restringían su derecho a la celebración de elecciones libres protegido por el citado art. 3 del Protocolo 1, beneficiando además a los dos partidos más consolidados en el Congreso de los Diputados y obstaculizando el derecho de los ciudadanos a participar en la vida política (votar y presentarse a las elecciones) en condiciones de igualdad (art. $14 \mathrm{del}$ Convenio en relación con el art. 3 del Protocolo 3).

A este respecto, el TEDH señaló que, tal y como había indicado anteriormente, los derechos a votar y presentarse a las elecciones protegidos por dicho artículo no son absolutos, lo cual dejaba espacio para «restricciones implícitas» ${ }^{181}$, por lo que los Estados gozaban de un amplio margen de apreciación en esta esfera ${ }^{182}$.

El Tribunal consideró que la obligación de recibir un número de firmas de un mínimo del $0,1 \%$ de los votantes de la circunscripción electoral había sido analizada por el Tribunal Constitucional, quien había considerado que dicha restricción tenía como objetivo mantener y mejorar el buen funcionamiento del sistema electoral y evitar la proliferación de partidos políticos que no disfrutaran de un apoyo mínimo por parte de la población ${ }^{183}$. Asimismo, el referido límite tenía también como objetivo la optimización de la asignación de los recursos públicos en la organización del proceso electoral, evitando además la confusión entre el electorado provocada por la proliferación de grupos que no podían asumir una responsabilidad política, todo lo cual además facilitaba alcanzar un consenso parlamentario ${ }^{184}$.

Basándose, inter alia, en la decisión recaída en el caso Mihaela Mihai Neagu c. Rumanía ${ }^{185}$, el Tribunal consideró que la medida estaba justificada por razones políticas e institucionales. El Tribunal añadió que dicha limitación era proporcional, todo ello con base en las directrices publicadas por la Comisión de Venecia ${ }^{186}$.

electores inscritos para votar en la circunscripción. A los electores se les permite únicamente prestar su firma para una candidatura.

180 El cual estipula que el plazo para recoger las firmas comienza a contar desde el día de la convocatoria de elecciones.

181 Soberanía de la Razón v. Spain, supra, párr. 24.

182 Idem.

183 Ibid., párr. 26.

184 Idem.

185 Mihaela Mihai Neagu v. Rumania (dec.), núm. 66345/09, párr. 34.

186 Soberanía de la Razón v. Spain, supra, párr. 27, en el que se hace referencia al Código de Buenas Prácticas en Materia Electoral de la Comisión de Venecia de 2002. 
Por otro lado, en relación con la obligación de que los votantes solo tenían permitido prestar su firma a una candidatura (art. 169.3 de la Ley Electoral), el Tribunal determinó que dicha limitación servía a un propósito legítimo, que no es otro que el de asegurar que los partidos tengan un apoyo mínimo por parte del electorado, lo cual no se podía considerar arbitrario o desproporcionado ${ }^{187}$. En lo que respecta a la obligación de recolectar firmas en un tiempo determinado, el Tribunal manifestó que los demandantes no habían demostrado las razones por las cuales se podría entender que el tiempo otorgado era insuficiente ${ }^{188}$.

Con respecto a la posible violación del art. 14 del Convenio puesto en relación con el art. 3 del Protocolo $\mathrm{n}^{\mathrm{o}} 1$ y la presunta violación del art. 1 del Protocolo $\mathrm{n}^{\mathrm{o}} 12$ del Convenio, el Tribunal reiteró que la discriminación significa «tratar de forma diferente, sin un objetivo y justificación razonables, a personas en situaciones similares» ${ }^{189}$. En el presente caso el Tribunal se adhirió a lo ya indicado a nivel interno por el Tribunal Constitucional, confirmando que dicho trato tenía una justificación objetiva y razonable a la vista del objetivo perseguido por el art. 169.3 de la Ley Electoral, en virtud del cual a los partidos sin representación se les podía solicitar que demostraran un mínimo de avales, lo cual se podía presumir en el caso de los partidos con representación ${ }^{190}$. Por todo lo anterior, el Tribunal declaró la demanda inadmisible.

El caso Dorado Baúlde c. España ${ }^{191}$ también presenta cierta relevancia por cuanto es la primera vez que el Tribunal tiene la oportunidad de pronunciarse sobre el alegado limitado alcance del recurso de casación como segunda instancia y su eventual conformidad con el art. 2 del Protocolo $7^{192}$. En el presente caso, el demandante había sido condenado en primera instancia por un delito de tráfico de drogas por la Audiencia Nacional. El demandante, basándose en la jurisprudencia emanada de varias decisiones emitidas contra España por el Comité de Derechos Humanos de la ONU, alegó que el limitado alcance del

187 Ibid., párr. 28

188 Ibid., párr. 29.

189 Ibid., párr. 33.

190 Ibid., párr. 34.

191 Dorado Baúlde v.Spain (dec.), núm. 23486/12.

192 El cual dispone lo siguiente: «1. Toda persona declarada culpable de una infracción penal por un tribunal tendrá derecho a que la declaración de culpabilidad o la condena sea examinada por una jurisdicción superior. El ejercicio de ese derecho, incluidos los motivos por los cuales pueda ser ejercitado, se regularán por ley. 2. Este derecho podrá ser objeto de excepciones en caso de infracciones de menor gravedad según las defina la ley, o cuando el interesado haya sido juzgado en primera instancia por el más alto tribunal o haya sido declarado culpable y condenado al resolverse un recurso contra su absolución». 
recurso de casación, en el cual el Tribunal Supremo no puede realizar un nuevo análisis de las pruebas y los hechos, contravenía el derecho a un recurso en segunda instancia prescrito en el ya citado art. 2 del Protocolo 7.

No obstante lo anterior, el Tribunal consideró que, tal y como quedó plasmado en el informe explicativo (explanatory report) de dicho protocolo, los Estados miembros poseen un amplio margen de apreciación a la hora de determinar el ámbito de protección del citado artículo, lo cual les permite decidir si dicho recurso versará sobre cuestiones de hecho y de derecho o únicamente sobre cuestiones de derecho. Sentado lo anterior, el Tribunal declaró la inadmisibilidad del recurso por manifiesta falta de fundamentación con arreglo a los apartados 3 y 4 del art. 35 del Convenio.

Por último, citaremos el caso Otegi Mondragón y otros c. España ${ }^{193}$, en el cual el Tribunal declaró inadmisible parcialmente la demanda interpuesta en nombre de los demandantes, mientras que otra parte fue comunicada al Gobierno para que efectuase las oportunas alegaciones (observaciones escritas).

Dicho caso versa sobre la alegada falta de imparcialidad de los magistrados de la Audiencia Nacional y del Tribunal Constitucional en el marco de un procedimiento penal en el que los demandantes fueron enjuiciados por pertenencia a banda terrorista.

En lo que respecta a la decisión de inadmisibilidad, la misma hace referencia, en concreto, a la alegada falta de imparcialidad de dos magistrados del Tribunal Constitucional (P. C. y N. R.). En primer lugar, los demandantes alegaban que un miembro del Tribunal Constitucional adolecía de la imparcialidad debida, toda vez que había sido miembro del Partido Popular, el cual, según los demandantes, había expresado públicamente opiniones, a través de varios portavoces, sobre el proceso penal aludiendo a la responsabilidad penal de los demandantes.

Asimismo, los demandantes también alegaron que otro de los miembros del Tribunal Constitucional no fue imparcial debido a que había sido previamente fiscal general del Tribunal Supremo en un procedimiento de ejecución en virtud del cual se pretendía la ilegalización del partido político SORTU (del cual los demandantes eran miembros) sobre la base de que dicho partido era una continuación del partido político HERRI BATASUNA, el cual ya había sido declarado ilegal por los tribunales españoles al ser considerado como un instrumento de la organización terrorista ETA para poder tener presencia en las instituciones públicas representativas.

193 Otegui Mondragon and others v. España (dec.), núms. 4184/15, 4317/15, 4323/15, 5028/15, 5053/15; 3 de noviembre de 2015. 
Según el Tribunal, ambos magistrados superaban el test subjetivo de imparcialidad, toda vez que no se desplegó ni una prueba al respecto que pudiera acreditar un comportamiento visiblemente parcial ${ }^{194}$. Ya solo restaba el test objetivo. Con respecto al primer magistrado, el TEDH observó que dicho magistrado únicamente había sido miembro de dicho partido y que en ningún momento había asumido funciones de dirección dentro del partido. El Tribunal declaró que los miedos de los demandantes no resultaban «objetivamente justificados» y que el mero hecho de haber pertenecido a un partido político no implicaba la automática pérdida de imparcialidad ${ }^{195}$. Con respecto al segundo magistrado, el Tribunal tomó como base lo indicado por el Tribunal Constitucional en el recurso de amparo presentado por los demandantes al señalar que los hechos discutidos en el procedimiento de ejecución eran completamente diferentes a los del proceso penal. El Tribunal se adhirió a las observaciones del Tribunal Constitucional y añadió que no se había probado ningún nexo entre los hechos discutidos en el procedimiento anterior de ejecución y este ${ }^{196}$. A la vista de todo lo anterior, el Tribunal declaró esta parte de la demanda inadmisible.

194 Ibid., párrs. 22 y 32.

195 Ibid., párr. 27.

196 Ibid., párr. 33. 
